\title{
Changing the World and Changing the Self: A Two-Process Model of Perceived Control
}

\author{
Fred Rothbaum \\ Tufts University
}

\author{
John R. Weisz \\ University of North Carolina at Chapel Hill
}

\author{
Samuel S. Snyder \\ North Carolina State University
}

\begin{abstract}
There is extensive evidence that people strongly value and are reluctant to relinquish the perception of control. Yet, both helplessness and locus of control theorists interpret various "inward" behaviors (passivity, withdrawal, and submissiveness) as signs of relinquished perceived control. As evidence, they note that inward behavior frequently is accompanied by causal attributions to limited ability, chance, and powerful others-all attributions that suggest uncontrollability. In contrast, we claim that these attributions and the behaviors to which they relate may often reflect a type of perceived control that is generally overlooked. People attempt to gain control not only by bringing the environment into line with their wishes (primary control) but also by bringing themselves into line with environmental forces (secondary control). Four manifestations of secondary control are considered: (a) Attributions to severely limited ability can serve to enhance predictive control and to protect against disappointment. Passive and withdrawn behaviors reflect the attempt to inhibit unfulfillable expectations. (b) Attributions to chance can reflect illusory control, since people often construe chance as a personal characteristic akin to an ability ("luck"). Individuals who make attributions to chance may exhibit passivity and withdrawal in skill situations, reserving energy and emotional investment for situations that allow them to capitalize on their perceived strength-that is, being lucky. (c) Attributions to powerful others permit vicarious control when the individual identifies with these others. Submission to a powerful leader, a group, or a deity sometimes enables the individual to join in their power. (d) All of the preceding attributions may foster interpretive control, in which the individual seeks to understand and derive meaning from otherwise uncontrollable events in order to accept them. When perceived control is recognized in both its primary and secondary forms, a broad range of inward behaviors can be seen as efforts to sustain rather than relinquish the perception of control.
\end{abstract}

Factor analytic studies with children (reviewed in Achenbach \& Edelbrock, 1978) and systematic observations of adults (e.g., Beck, 1967; Marks, 1977) have identified a

This article was funded in part by National Institute of Mental Health Grant 1-RO1-MH-34210-01.

The authors are indebted to Camille Wortman for her unusually thorough review of a draft of this article. Her comments added depth and clarity to many of the central points.

Requests for reprints should be sent to Fred Rothbaum, Department of Child Study, Tufts University, Medford, Massachusetts 02155. set of interrelated problem behaviors including passivity, withdrawal, and submissiveness (hereafter referred to as inward behavior). The popularity of the learned helplessness model (Abramson, Seligman, \& Teasdale, 1978; Seligman, 1975) is due largely to its lucid account of at least some of these seemingly maladaptive behaviors (especially passivity and withdrawal). Adherents of this model maintain that perceptions of uncontrollability are frequent antecedents of inward behavior. In support of this view, a number of studies indicate that 
experiences designed to induce perceptions of uncontrollability lead to decreased learning, decreased persistence, and depressed affect-key components of inward behavior.

The locus of control literature also seems to link perceived uncontrollability and inward behavior. Persons with an external locus of control-those who see circumstances, chance, and powerful others as controlling outcomes-are, in general, more likely to manifest such inward behaviors as passivity, withdrawal, compliance, conformity, and depressive symptomatology than are persons with an internal locus of control-those who see their own effort or ability as controlling outcomes (for reviews see Lefcourt, 1976, 1980; Phares, 1976; Rothbaum, Wolfer, \& Visintainer, 1979). ${ }^{1}$ Also relevant here are studies in which perceptions of uncontrollability have been manipulated and locus of control has been assessed (Cohen, Rothbart, \& Phillips, 1976; Diener \& Dweck, 1978; Dweck, 1975; Gregory, Chartier, \& Wright, 1979; Hiroto, 1974; Pittman \& Pittman, 1979). While the findings entail complexities which will be dealt with later in the article, in general they indicate that externality and manipulations designed to decrease perceived control are both associated with inward behavior (also see Coyne, Metalsky, \& Lavelle, 1980; Janoff-Bulman \& Brickman, 1980). Because of their considerable overlap in this respect, the helplessness and locus of control positions are referred to collectively as the uncontrollability model of inward behavior.

In addition to their focus on perceptions of control, uncontrollability theorists also emphasize the motivation for perceived control. The general assumption, supported by research, is that perceptions of uncontrollability and decreased motivation for control fuel one another in a downward spiral (DuCette \& Wolk, 1973; Koller \& Kaplan, 1978). The resulting inward behavior is seen, in part, as a motivational deficit, that is, as a consequence of relinquishing the motivation for control (Seligman, 1975).

Uncontrollability theorists' emphasis on the motivation for perceived control has many roots in earlier theorizing, dating at least from Groos's (1901) observation that children derive pleasure from opportunities to control stimulation. Theorists from a wide variety of perspectives have been emphatic about the importance of control: Adler (1956) depicted control as an intrinsic "necessity of life"; Malinowski (1955) noted among primitives a "desperate" need to believe they could master the world; White (1959), in a now classic review of the literature on "effectance motivation," refers to a pervasive, intrinsic need to exercise control over the environment; DeCharms (1968) argued that the urge to be effective in changing the environment is "man's primary motivational propensity." Evidence of motivation for perceived control can be found in a wide variety of research areas. It is prominent, for example, in research on (a) helplessness and locus of control (briefly reviewed in this article), (b) perceived "contingency" in infancy (e.g., Finkelstein \& Ramey, 1977; Gunnar-Vongnechten, 1978; Watson, 1967), (c) effectance and mastery motivation in childhood (reviewed by Harter, 1978), (d) intrinsic motivation, both in children (e.g., Lepper, Greene, \& Nisbett, 1973) and adults (Deci; 1975), (e) the self-serving bias in children (Weisz, 1980, 1981) and adults (Snyder, Stephan, \& Rosenfield, 1978; Zuckerman, 1979), (f) feelings of competence in the elderly (Langer \& Rodin, 1976; Schultz, 1980), and (g) the attractiveness and adaptive value of different types of perceived control, such as predictability (Av-

${ }^{1}$ Rotter (1966), in original formulation of the locus of control construct, defined internality in terms of both self-contingency and self-causality. This definition leads to confusion in the case of certain attributions, such as attributions to limited ability, which imply an absence of self-contingency (jndependence between the self's response and the environmental outcomes) but the presence of self-causality (the self's inability is the ascribed cause of the environmental outcome). In this article we equate internality with contingency and externality with noncontingency. This position conflicts with the position of the locus of control theorists who depict limited ability as an internal attribution (e.g., Abramson et al., 1978; Weiner, 1974) but is consistent with the position of other locus of control theorists who see limited ability attributions as contributing to the belief that effort does not make a difference - a belief that exemplifies externality (e.g., Cohen, Rothbart, \& Phillips, 1976; Diener \& Dweck, 1978; Lefcourt, 1976). For a fuller discussion of this topic, see Janoff-Bulman (1979) and Rothbaum (1981). 
erill, 1973; Burger \& Arkin, 1980; Lefcourt, 1973). ${ }^{2}$

Motivation for perceived control and its corollary, aversiveness of perceived uncontrollability, are cornerstones of the uncontrollability formulation (Lefcourt, 1976; Seligman, 1975). Yet ironically, uncontrollability theorists may be shortchanging the generality and potency of this motive. In this article we argue that the motivation to feel "in control" may be expressed not only in behavior that is blatantly controlling but also, subtly, in behavior that is not. In some cases, inward behavior may reflect a relinquishing of the powerful motive for perceived control. In other cases, however, such behavior may be initiated and maintained in an effort to sustain perceptions of control. This effort is particularly likely when the inward behavior helps prevent disappointment, when it leads to a perception of alignment with forces such as chance or powerful others, and when it is accompanied by attempts to derive meaning from a situation. The uncontrollability model does not explain any of these phenomena.

A related problem is that the uncontrollability model does not account for the persistence of some inward behavior. This persistence is evident in research on depressives" negative response set (Beck, 1967) and in research on obsessive compulsives' perseverative thoughts and actions (Rackman \& Hodgson, 1980). There is even evidence of persistence in the research on helplessness. For example: dogs exposed to uncontrollable shock subsequently have to be dragged into a safety area (Seligman, 1975); individuals subjected to uncontrollable social situations manifest increased perseverative behavior (Goetz \& Dweck, 1980); and individuals exposed to unsolvable tasks go out of their way to find reasons why they cannot succeed (Diener \& Dweck, 1978; Seligman, 1975). These findings, and others reviewed later in the article, indicate that persons sometimes actively undermine their own chances of success. In all of these cases, inward behavior persists well beyond the time during which it is adaptive by rational standards, and it persists despite attempts by others to alter it. It is largely this quality of persistence that prompts analytically oriented theorists to speculate about deeper motives and to label the behavior "neurotic" (e.g., Kessler, 1966; Wolman, 1965). Such persistence suggests that the behavior does satisfy some underlying purpose and that it does not merely reflect a "deficit" in motivation .

These phenomena, we suspect, can best be understood by broadening our conception of control and how it is manifest in everyday life. Simply stated, our proposal is this: Because control is so valued, the quest for it is rarely abandoned; instead, individuals are likely to shift from one method of striving for control to another. The uncontrollability model and the present formulation, then, disagree as to how frequently motivation for control is abandoned. This disagreement goes hand in hand with a related disagreement about the pervasiveness of perceived uncontrollability. Many situations that according to uncontrollability theorists indicate a perception of uncontrollability are situations in which we believe perceived control is actually a major dynamic (cf. JanoffBulman \& Brickman, 1980). In large part, these disagreements regarding motivation and perception hinge on different conceptualizations of control. A reasonable next step, then, is to contrast uncontrollability theorists' definition of control with the definition we propose.

\section{Definitions of Control}

Helplessness and locus of control theorists conceptualize perceived control similarly. Both place a major emphasis on the contingency between action and outcome (Rotter, 1966; Seligman, 1975). Related constructs such as perceived choice and competence also figure prominently in both helplessness theory (e.g., Langer \& Benevento, 1978)

\footnotetext{
${ }^{2}$ Recently, some authors claimed that the motivation for control is not as pervasive as has typically been assumed (Brehm \& Brehm, 1981; Rodin, Rennert, \& Solomon, 1980). They take issue with the notion of a generalized motivation to seek control and with the notion that control is always desirable. As already noted, we believe there is considerable formal and informal evidence of a generalized motivation to seek control, but we also recognize that much more research is needed to resolve this matter. Later in this article we briefly consider the evidence indicating that control sometimes appears undesirable (see pp. 15-16).
} 
and locus of control theory (e.g., Lefcourt, 1976; Rotter, 1966; see also Weisz \& Stipek, in press). In each case the individual's ability to change the environment to fit the self's needs is emphasized. Seligman's definition of contingency, for example, makes it clear that the individual's actions must lead to change in the environment. Even White, who has identified myriad expressions of control, emphasizes throughout his formulation the individual's ability to affect the environment.

Unlike most uncontrollability theorists, we conceive of control as a two-process rather than a one-process construct. The first process involves attempts to change the world so that it fits the self's needs. When this process is salient, we use the expression primary control. It is our belief that uncontrollability theorists have equated control with primary control and have all but ignored a second process we wish to highlight-attempts to fit in with the world and to "flow with the current." We refer to this process as secondary, and when it is salient, we employ the expression secondary control.

The attempt to change things that offer resistance, which characterizes primary control, is apt to produce some satisfying successes but also some disappointing failures. The attempt to adjust to resistances, which characterizes secondary control, is apt to be experienced as safer and to lead to less extreme highs and lows. Neither process is thought to exist in pure form; often both processes are intertwined, as when persons negotiate and compromise (Lazarus, 1981). Often there is vacillation between the two processes, as when persons shift between phases of encounter and retreat in coping with a physical disability (Shontz, 1975; Silver \& Wortman, 1980). Thus, the differences between primary and secondary control should be thought of as differences in emphasis.

A rough analogy can be drawn between this primary/secondary relationship and the complementary processes of assimilation and accommodation as described by Piaget (1970) in his theory of cognitive development. Assimilation denotes the tendency to perceive the environment in ways consistent with one's existing cognitive structures. In extreme cases of both assimilation and primary control, the individual, in a sense, places his or her desires above the demands of reality. In complementary fashion, accommodation is the tendency to modify one's cognitive structures in an attempt to effect a better fit with reality. As is true of secondary control, in extreme accommodation the demands of reality overwhelm the self's desires (cf. Lazarus \& Launier, 1978, p. 314). Averill (1973) highlights this accommodative process when he notes that control increases to the extent that the individual is able to "accommodate to necessity" (cf. Chein, 1972; Kelly, 1955). Piaget and other cognitive developmental theorists argue that the goal of development is equilibrationthe coordination of assimilation and accommodation-so as to optimize the individual's adaptation to the environment. Similarly, in the model proposed here, optimal adaptation is defined as the coordination of primary and secondary control.

The terms primary and secondary are adopted for several reasons. First, they reflect the fact that one process (primary) has generally received more attention than the other (secondary). Second, the terms distinguish between the presence and absence of more powerful controlling agents: If the self is the most powerful agent, then control is primary; if more powerful agents are acknowledged (e.g., a task that one's severely limited ability makes insurmountable, chance, or a powerful other person), the self's control is secondary. Another virtue of using the terms primary and secondary is that they capture differences in the temporal sequence of the control processes they delineate. Secondary control is most likely to occur after attempts at primary control have failed. Naturalistic evidence on the temporal sequence of the two types of control indicates that behaviors reflecting secondary control (passivity, withdrawal, and submissiveness) are a late stage of reaction to stress; typically they are preceded by a stage of anger and protest-behaviors that we associate with primary control (for evidence regarding stages see Baum, Aiello, \& Calesnick 1978; Klinger, 1975; Mann \& Dashiell, 1975; Rothbaum, 1980; Wortman \& Brehm, 1975). However, the evidence is far from clear-cut 
(Silver \& Wortman, 1980), and we suspect that vacillation between primary and secondary control is common.

The primary/secondary distinction we propose resembles in certain respects the offensive/defensive distinction frequently employed in the psychological literature. One problem with the latter is that it has been used to refer to such a broad variety of phenomena that its meaningfulness is diminished. Secondary control differs from defensiveness in that it does not refer to all attempts to neutralize instinctual urges (as does use of the term defensive in psychoanalytic writings), and it does not refer to attempts to maintain self-esteem by forgetting or denying the occurrence of failure (as does use of the term defensive in attribution theory literature). In fact, we would generally regard the protection of self-esteem through denial as an attempt to maintain belief in the eventual effectiveness of primary control-the ability to change the environment.

\section{Proof of Uncontrollability}

Differences between our definition of control and that advocated by uncontrollability theorists lead to differences in the criteria used to infer uncontrollability. In this section we attempt to explain these differences.

\section{The Uncontrollability Model}

Uncontrollability theorists rely on several kinds of information in deciding whether or not a given situation is perceived as uncontrollable. First, the individual's behavior itself may indicate perceived uncontrollability. Passive, withdrawn, and to a lesser extent, submissive behaviors often do not serve instrumental ends (e.g., to obtain a desired goal, solve a problem, or terminate an aversive event). In such cases, uncontrollability theorists typically infer an abandoning of attempts to control. They are particularly likely to draw this inference when there is a cluster of the above behaviors. However, uncontrollability theorists recognize a variety of exceptions to this rule, and they do not hinge their proof of uncontrol- lability on this evidence alone. More compelling, they believe, are the causal attributions that are frequently found in conjunction with these inward behaviors. Both helplessness theorists (Hiroto \& Seligman, 1975; Klein \& Seligman, 1976; Miller \& Seligman, 1975) and locus of control theorists (Lefcourt, 1976; Phares, 1976; Rotter, 1966) claim that the tendency to attribute failure to severe limitations in ability, ${ }^{3}$ to chance, and to powerful others relates to the tendency to engage in inward behavior (cf. Wortman \& Brehm, 1975), especially when the attributions are global and stable (Abramson, Seligman, \& Teasdale, 1978). Because these theorists equate control with the ability to change the environment, they maintain that these attributions reflect perceived uncontrollability.

Probably the most widely cited evidence of perceived uncontrollability is that the above attributions and inward behaviors both seem to result from manipulations designed to induce perceived uncontrollability. The demonstration of these causal connections is a major objective of helplessness research. Manipulations such as noncontingent aversive events (e.g., loud noise, electric shock) and unsolvable problems have repeatedly been associated with the above attributions. Zuckerman (1979), for example, found that failure experiences led to an increased occurrence of external attributions in 27 of the 38 studies he reviewed. Similarly, persons high in externality on locus of control measures tend to have socialization histories indicating repeated experiences of failure (Lefcourt, 1976; Crandall, Note 1).

Manipulations of uncontrollability have been shown to lead to inward behavior, particularly passivity (e.g., Benson \& Kennelly, 1976; Cohen, Rothbart, \& Phillips, 1976; Glass \& Singer, 1972; Griffith, 1977; Hir-

\footnotetext{
${ }^{3}$ Although locus of control theorists refer to attributions to circumstances rather than to attributions to limited ability, the major circumstance they consider is task difficulty. Thus, there is substantial overlap in these formulations. The qualifier "severe" is added because of findings that attributions to slight to moderate limitations in ability lead to noninward behavior (Pittman \& Pittman, 1979; Roth \& Kubal, 1975; Tennen \& Eller, 1977).
} 
oto, 1974; Hiroto \& Seligman, 1975; Roth \& Kubal, 1975; Tennen \& Eller, 1977; Thornton \& Jacobs, 1971; for a review see Roth, 1980). There is also evidence that withdrawn and submissive behaviors are associated with the aforementioned attributions and manipulations. Because previous reviews of the uncontrollability model have given less attention to the latter behaviors, a brief consideration of them is appropriate here.

Most uncontrollability theorists would probably regard withdrawal as a manifestation of perceived uncontrollability (e.g., Goetz \& Dweck, 1980). As Carver (1979) suggested, the "impulse to withdraw is basic to a wide variety of helplessness effects" ( $p$. 1276). However, Carver also noted that many helplessness paradigms have failed to include opportunities for physical withdrawal. When physical withdrawal is prevented, he argued, subjects may engage in cognitive withdrawal-a mental dissociation from the task. The decreased learning found in many helplessness studies could be regarded as evidence of this cognitive withdrawal (Carver, 1979).

Submissiveness is another behavior that has been linked to perceived uncontrollability. Locus of control theorists explicitly draw connections between submissiveness and perceived uncontrollability (Lefcourt, 1976). Although helplessness theorists have failed thus far to elaborate this connection, the helplessness model is relatively new and open to extension in this direction. Seligman (1975) seemed favorably inclined toward just such an elaboration of the helplessness model when he reported anecdotal evidence of a connection between helplessness and submissiveness (p. 25). In at least one study, helplessness was operationalized as a relatively submissive "going to get the experimenter" as opposed to taking more independent action (Roth \& Bootzin, 1974). Findings from this study indicated greater submissiveness following manipulations of uncontrollability (see also Langer \& Benevento, 1978). A link between submissiveness, helpless behavior, and perceived uncontrollability has also been noted in studies involving retarded children exposed to recurring fail- ure experiences (Floor \& Rosen, 1975; Weisz, 1979, in press; Yando \& Zigler, 1971).

To summarize, uncontrollability theorists rely on several types of evidence in substantiating their claims: (a) The inward behaviors in and of themselves suggest perceived uncontrollability, especially when they cooccur. (b) These behaviors are associated with causal attributions indicating perceived uncontrollability. (c) Both the behaviors and the attributions have been shown to result from experiences designed to induce perceived uncontrollability. Although uncontrollability theorists to date have focused more on passivity than on withdrawal and submissiveness, the evidence reviewed here demonstrates that the model has been used to explain the latter behaviors as well.

\section{A Two-Process Model}

The uncontrollability model and the position we propose lead to different criteria of uncontrollability. We claim that attempts to fit more effectively with the world constitute a process of secondary control; if we are right, attributions and behaviors cited above do not necessarily provide proof of perceived uncontrollability. There is a definitional difference here, but its importance should not be exaggerated. Whether one chooses the term control when the secondary process is salient is not crucial. Rather, at issue is how the attributions and behaviors reviewed above may be most usefully explained. We maintain that underlying these attributions and behaviors is a powerful motivation to fit in with the environment. In contrast, uncontrollability theorists highlight the absence of attempts to change the world and the absence of motivation for control (cf. Wortman \& Brehm, 1975). This is the point of contention.

In four subsequent sections we review research involving causal attributions to severely limited ability, to chance, and to powerful others, along with the respective inward behaviors to which they frequently relate. These combinations of attribution and behavior, we argue, often reflect a perception of secondary control. To support our two- 
process model, we will attempt to show that these attributions and behaviors are accompanied by forms of persistence (e.g., undermining success, increasing effort on chance tasks, seeking out powerful others, and increased attributional activity) that indicate a striving for secondary control. To introduce the two-process model, we first provide a brief overview.

Attributions to severely limited ability can afford the individual control in the form of making the best of a situation that is perceived as difficult or impossible to alter. This control stems from the ability to predict the uncontrollable outcome (or its recurrence) and from the adjusting of the self's expectations accordingly. Adjustment of expectations is particularly important because unfulfilled expectations undermine perceived control; obversely, fulfilled expectations heighten perceived control. Because Averill (1973), Burgess and Holmstrom (1979), Lazarus (1966), Miller and Grant (1980), and other theorists concerned with this kind of control all emphasize predictability, we refer to it as predictive control.

Attributions to chance permit what is referred to here as illusory control. Persons sometimes attempt to associate themselves with chance so as to share in the power of this larger force. Chance is viewed as a property of the individual; often persons speak of luck as an ally that they can "rely on," and of being "born lucky," seemingly regarding luck as a type of control. Through various means-superstitious behavior, rituals, and, more simply, investing energy in chance-determined situations rather than in skill-determined situations-people attempt to align themselves with chance.

Attributions to powerful others are similar to attributions to chance in that they permit association with a more powerful force. Although such vicarious control may sometimes serve instrumental ends, it often appears to function as an end in its own right. That is, persons sometimes associate with others simply for the sake of sharing psychologically in the others' control. Vicarious control, then, is similar to the phenomena of identification and deindividuation, in which individuals submerge a sense of self in order to enhance a sense of close association with a more powerful entity.

Finally, all of the above attributions enable the self to derive meaning from otherwise uncontrollable experiences. We refer to the ability to interpret events so as to better understand and accept them as interpretive control (Averill, 1973; Frankl, 1963; Garber, Miller, \& Abramson, 1980).

The predictive, illusory, vicarious, and interpretive control described above are all instances of what we label secondary control. In each case, a tendency to change the self so as to fit more effectively with the environment overshadows a tendency to change the environment so that it fits the self's needs. We believe that failure to consider these and other instances of secondary control underlies uncontrollability theorists' mistaken conclusion that perceived uncontrollability and abandoning the motive to control are so prevalent.

Although uncontrollability theorists might acknowledge the existence of predictive, illusory, vicarious, and interpretive control, they would probably emphasize their primary aspects. Most likely, predictive control would be defined as a belief in the ability to predict events and thereby plan a successful task outcome; illusory control would be defined as an irrational belief that persons can, through effortful action, influence chancedetermined (as well as skill-determined) outcomes (e.g., superstitious behavior through which they erroneously believe their actions determine chance outcomes); vicarious control would be defined as a belief that one can gain control through powerful others, either by manipulating their actions or by imitating them; and interpretive control would be defined as a belief that one can find the meaning of a problem and thereby solve it. (See Table 1 for a summary of the primary and secondary manifestations of predictive, illusory, vicarious, and interpretive control.) The key difference between primary and secondary control is that in the former case the goal is to change the environment whereas in the latter case the goal is to fit in with the environment. The above instances of primary control are dissimilar to instances of secondary control in that they are unlikely 
to accompany attributions to severely limited ability, to chance, or to powerful others and they are unlikely to accompany noninstrumental behaviors of a passive, withdrawn, or submissive kind.

In the following four sections, we attempt to show that many situations previously thought to involve perceived uncontrollability are ones in which persons strive for secondary control. These sections are organized by the four kinds of secondary control just reviewed-predictive, illusory, vicarious, and interpretive. Because we agree with uncontrollability theorists that consideration of behaviors, attributions, and precipitating events is essential, evidence regarding all three factors will be treated in each section. To support our claims we attempt to provide behavioral and self-report evidence of striving for secondary control in situations in which persons (a) manifest passive, withdrawn, and submissive behavior; (b) attribute outcomes to severely limited ability, chance, or powerful others; and (c) have just experienced manipulations designed to increase perceived uncontrollability.

\section{Predictive Control}

When an attribution to severely limited ability occurs in conjunction with passive or withdrawn behavior, and when the situation

Table 1

Primary and Secondary Processes

\begin{tabular}{|c|c|c|}
\hline $\begin{array}{l}\text { Type of } \\
\text { control }\end{array}$ & $\begin{array}{l}\text { Salient } \\
\text { process }\end{array}$ & Description \\
\hline \multirow[t]{2}{*}{ Predictive } & Primary & $\begin{array}{l}\text { Attempt to predict events so as to succeed at them. } \\
\text { Active behavior and attributions to the self"s effort } \\
\text { and ability are likely, especially in tasks of moderate } \\
\text { difficulty. }\end{array}$ \\
\hline & Secondary & $\begin{array}{l}\text { Attempt to predict events so as to avoid disappointment. } \\
\text { Passive and withdrawn behavior, especially in tasks of } \\
\text { moderate difficulty. Active, persistent behavior in } \\
\text { extremely easy or difficult situations. Attributions to } \\
\text { severely limited ability are likely. }\end{array}$ \\
\hline
\end{tabular}

Illusory Primary

Attempt to influence chance-determined outcomes. Active behavior in chance and skill situations and attributions to the self's effort and ability are likely.

Secondary

Attempt to associate with chance. Active behavior in chance situations but passive and withdrawn behavior in skill situations and attributions to chance are likely.

Vicarious Primary

Attempt to manipulate powerful others or imitate their power or ability. Instrumental submissive behavior or manipulative behavior and attributions to the self's effort and ability are likely.

Secondary

Attempt to associate with powerful others. Noninstrumental, submissive behavior and attributions to others are likely.

Attempt to understand problems so as to be able to solve them or otherwise master them. Active behavior and attributions to the self's effort and ability are likely.

Secondary

Attempt to understand problems so as to derive meaning from them and to accept them. Passive, withdrawn, and submissive behavior and attributions to severely limited ability, chance, and powerful others are likely. 
is one in which effort would likely produce a desired outcome, uncontrollability theorists typically conclude that the individual has given up-has abandoned the attempt to exercise control. In contrast, we believe that in certain situations the combination of an attribution to severely limited ability and passive or withdrawn behavior allows for predictive control. In the present context, the expression predictive control refers to the ability to predict aversive events to avoid disappointment (cf. Averill, 1973; Lazarus, 1966; Miller \& Grant, 1980).

Individuals who have repeatedly experienced failure sometimes avoid tasks completely or participate with minimal effort, even when they realize that they have a good chance of success, In justifying their seemingly self-defeating behavior, these individuals often maintain that their ability to avoid disappointment is their last line of defense. The aversiveness of disappointment was vividly demonstrated on a national scale in the United States during the Iranian hostage crisis of 1980-1981. Many Americans would have echoed the feelings of a parent of one of the hostages: "We've been disappointed so many times. Now I won't allow myself to believe in the eventual success of the negotiations until I see them [the hostages] step off the plane." Disappointment is so aversive, we believe, because it adds the insult of secondary uncontrollability (not being prepared for the outcome) to the injury of primary uncontrollability (not being able to alter the outcome). We believe that individuals actively strive to avoid disappointment and that a major objective in doing so is to gain an increased sense of secondary control. To support our claim, we will provide evidence that individuals exert effort and make sacrifices to avoid disappointment and that their objective is an increased sense of effectiveness. We will rely primarily on three bodies of literature: research directly concerned with disappointment, research on achievement motivation, and research on reactions to unpredictable stress.

Mettee (1971) provided the clearest empirical support for the position that disappointment is actively avoided. He argued that persons avoid success when it is per- ceived to increase the probability of unfulfillable expectations and thus of eventual disappointment. To test this notion, Mettee exposed subjects first to failure, then to success, and finally gave them the opportunity to accept or reject the success-that is, he readministered the test at which the subjects had just succeeded, thus providing them the opportunity to change their correct answers. Between failure and success experiences, some subjects were informed that an interview very likely confirming their initial failing performance would occur at the conclusion of the study; other subjects were assured that no further information was forthcoming. As predicted, the former group, for whom acceptance of success implied a greater vulnerability to disconfirmed expectations, was more rejecting of the success experience. To create a third condition, some of the subjects in the "future interview" condition were told that the forthcoming feedback would inevitably confirm their prior failure. Mettee hypothesized that when future failure was assured, disappointment would not be possible and that, as a consequence, subjects would accept success (i.e., not change their correct answers). His findings supported this hypothesis. Subjects accepted success in this condition, reasoned Mettee, because it was irrelevant to their future expectations. Subsequent studies in which different manipulations were employed to make success irrelevant have yielded similar findings (Brickman, Linsenmeier, \& McCareins, 1976; Maracek \& Mettee, 1972).

Additional evidence for the view that persons actively strive to avoid disappointment comes from Wortman, Costanzo, and Witt (1973), who gave subjects a "social perceptiveness task" with predetermined feedback. Regardless of whether feedback was positive or negative, subjects who thought they might be tested further were less likely to perceive themselves as capable than were subjects led to believe there would be no further testing. One interpretation of these findings is that subjects wanted to mitigate the possibility of disappointment in the new situation. Attributions to severely limited ability in these cases offer a distinct advantage: They minimize the possibility of the kind of discon- 
firmed expectation that is most disappointing. To expect success but instead to fail is a double defeat; one has failed not only as a performer of the task but also as a predictor of the outcome.

In an earlier pair of studies similar to Mettee's except that the possibility of subsequent feedback was not mentioned, Aronson and Carlsmith (1962) also found that subjects undermine unexpected success. They interpret these results as evidence for a desire to avoid inconsistency. Although there have been a few successful replications of the above results (Brock, Edelman, Edwards, \& Schuck, 1965; Cottrell, 1965; Haimowitz \& Haimowitz, 1966), most of the replication attempts have not been supportive (see Archibald, 1974, for a list of 10 such studies). Mettee's model provides an alternative explanation for both the effect and its equivocal support: Subjects sometimes reject success in order to avoid disappointment, but the degree to which success is rejected depends upon the degree to which factors contributing to fears of disappointment (e.g., threats of later feedback) are present.

Other consistency theorists have shown that subjects with low self-esteem prefer evaluators who provide mostly negative feedback to evaluators who provide mostly positive feedback (e.g., Backman \& Secord, 1959; Deutsh \& Solomon, 1959). Here again we take issue with the desire-for-consistency explanation and instead suggest that low self-esteem persons fear disappointment. Consistent with our view, Jones's (1973) examination of the relevant literature suggests that subjects in these studies often expect to be given another test in the future.

The reliance on avoidance of disappointment as a conscious strategy was investigated more directly in a study by Sidle, Moos, Adams, and Cady (1969). Persons who reported that they expect the worst as a means of coping tended to view themselves as passive, slow, changeable, and low in selfesteem. These are precisely the perceptions that have led previous researchers to infer an absence of perceived control.

A number of other findings, which do not directly address the issue of disappointment, can nonetheless be seen as relevant to this issue. In general, the findings indicate that persons low in self-esteem and persons exposed to failure show low preference for and low effort on tasks that offer moderate chances of success but high preference for and high effort on extremely easy or extremely difficult tasks. Before considering how avoidance of disappointment may usefully explain these findings, a brief review of the relevant literature is in order.

Atkinson's (1957, 1964) findings on achievement motivation are the best known in this area. He found an overall tendency for subjects to prefer moderately difficult tasks because they maximize the possibility of a meaningful success experience. Atkinson noted, however, that low self-esteem ("failure avoidant") persons tend to avoid moderate-level tasks (see also Kukla, 1974). The low self-esteem person, Atkinson believed, seeks to attenuate failure, and this can best be accomplished by maximizing the probability of success (very easy tasks) or by minimizing the shame of failure (very difficult tasks). Subsequent research by Karabenick and Yousseff (1968) showed that persons chronically concerned about failure perform better at tasks described as very difficult. Similarly, Shaban and Jecker (1968) showed that subjects exposed to a failure manipulation prefer evaluators who evaluate almost everyone positively or negatively to more moderate evaluators (who evaluate about half of the people positively).

Following in this line of research, Frankel and Snyder (1978) exposed subjects to unsolvable problems and subsequently assessed their passivity and withdrawal on either extremely difficult or moderately difficult tasks. According to Frankel and Snyder, helplessness theorists maintain that passivity and withdrawal result from perceived uncontrollability, and, by this logic, more of these behaviors would be expected on the extremely difficult tasks. Their own self-esteem/defensive-effort model, in contrast, leads to the conclusion that passivity and withdrawal reflect an attempt to excuse failure and that the need for such excuses is greater with moderately difficult tasks. Their results, indicating that passivity and withdrawal were greatest in the moderately difficult task con- 
dition, supported the self-esteem/defensiveeffort model.

Thus, there have been numerous studies, spanning over 20 years, indicating that persons with low self-esteem and persons exposed to failure tend to avoid tasks of moderate difficulty. Frankel and Snyder's explanation that these subjects are seeking an excuse for possible failure is an appealing one (see Snyder \& Wicklund, 1981, for an elaboration of this position). We believe, however, that avoidance of disappointment provides an equally appealing explanation. Subjects are unlikely to be disappointed by performance at very easy tasks because they will almost definitely succeed and are unlikely to be disappointed by performance at very difficult tasks because their expectations of success are very low. ${ }^{4}$ Moreover, there are two pieces of evidence that cast doubt on Frankel and Snyder's interpretation: (a) The subjects who exerted little effort on the moderately difficult tasks scored low in self-reports of esteem. (b) These subjects did not make a greater number of effort attributions for their failure (e.g., "I didn't try"). Neither finding fits with Frankel and Snyder's hypothesis; in contrast, both findings are consistent with our avoidance of disappointment hypothesis. We believe that the emphasis on the self-esteem/defensiveness explanation reflects psychologists' persistent focus on people's desire for primary control (clinging to the belief that the self can, ultimately, change the environment) and their perception that primary control is an unmitigated good (cf. Janoff-Bulman \& Brickman, 1980). Rather than clinging to a belief in primary control, we believe that persons sometimes actively oppose such beliefs, especially when these beliefs are seen as opening the floodgates of disappointment and, thus, as jeopardizing secondary control.

There is other evidence of the aversiveness of disappointment and of people's desire to avoid it through accurate prediction. Glass and Singer (1972) showed that a predictable (fixed interval) aversive event (loud noise) leads to fewer errors on a frustration task and fewer omissions on a task of caution and attentiveness than does an unpredictable (random) aversive event, even with fre- quency and intensity of aversive events identical across conditions (for reviews of related studies see Averill, 1973; Burger \& Arkin, 1980). Although aversiveness per se (intensity of noise) has some influence on performance, its effect pales in comparison with that of unpredictability. A number of other investigators also report that specific, accurate expectations can reduce the adverse effects of stressful procedures (Epstein, 1973; Janis, 1958; Johnson, 1973, 1975; Johnson \& Leventhal, 1974; Leventhal, Brown, Shacham, \& Engquist, 1979). In interpreting some of these findings, Lefcourt (1973, 1976) pointed out that prediction allows the individual to steel him- or herself to the aversive event and thus to not be caught off guard-that is, prediction protects against disappointment. In a similar vein, Miller (1980) espoused an "internality view of prediction" according to which preparing for the worst enables the individual to "match his or her internal state with external events" (cf. research on sensitization cited in Averill, 1973; Janis's, 1958, research on the "work of worry"). These authors would probably agree with our conclusion that predictability allows the individual to adjust to the uncontrollable event, thus making it, in a secondary sense, "controllable."

Also relevant here are studies showing that in some instances increased perception of opportunities for primary control can be stress inducing. Stress occurs when the available methods of control are ineffective, for example, when responses intended to terminate shock yield inconsistent or negative feedback (Weiss, 1968; 1971a, 1971b, $1971 \mathrm{c})$. In other cases, in which subjects are

\footnotetext{
${ }^{4}$ Trope (1975) and Trope and Brickman (1975) found evidence indicating that the major virtue of moderately difficult tasks is that they are typically high in "diagnosticity" (i.e., they are especially able to distinguish the competent from the incompetent). These authors suggested that very difficult tasks are appealing to failure-avoidant individuals because of their desire to avoid diagnosticity. This idea resembles our suggestion that very difficult tasks enable failure-avoidant individuals to avoid disappointment. Consistent with the diagnosticity view as well as with ours is recent evidence that persons made anxious about failure subsequently show less preference for highly diagnostic tasks (Schulz \& Hanusa, Note 3).
} 
given choices that do affect outcomes, but they lack the information necessary to increase the likelihood of a beneficial result, increased stress is also noted (Rodin, Rennert, \& Solomon, 1980). In the latter circumstances, increased control (choice) also leads to decreased self-esteem. It is interesting that when subjects are told that they are not expected to do well (a manipulation that is likely to mitigate perceived disappointment), the aversive effects of choice are not obtained. We maintain that in both of the above studies there is an inaccurate perception of opportunity for primary control that leads to an increase in unfulfillable expectations and thus to the likelihood of disappointment. The advantage of secondary control is the avoidance of this disappointment.

\section{Summary}

The evidence reviewed here suggests that attributions to severely limited ability and the passive and withdrawn behavior that often accompanies these attributions sometimes reflect the individual's striving for predictive control. Individuals who can accurately predict uncontrollable events can thereby avoid unfulfillable expectations (i.e., disappointment) that fuel the perception of uncontrollability. This tendency to adjust the self's expectations and behaviors to make them compatible with a difficult environment is an example of secondary control. The evidence reviewed here indicates that there is an increased desire for predictive control following uncontrollable experiences and that the striving for predictive control often takes the form of inward behavior. Moreover, there is evidence that this striving for predictive control, as shown by the avoidance of moderately difficult tasks, is likely to accompany attributions to severely limited ability (Kukla, 1974; Maracek \& Mettee, 1972). What is not yet available is evidence that persons in the situations described above actually perceive themselves as gaining predictive control. This evidence is especially needed because of the competing explanations for the phenomena in question.

This section and the sections that follow contain evidence of the existence of secondary control in situations previously thought to entail perceived uncontrollability. Several of the studies cited here (e.g., Frankel \& Snyder, 1978; Glass \& Singer, 1972; Mettee, 1971) employed manipulations of uncontrollability similar or identical to those employed in helplessness studies. It is possible that some subjects who appear to be giving up are in fact abandoning control, whereas other subjects who appear to be giving up are attempting to control disappointment.

\section{Illusory Control}

The treatment of illusory control and of attributions to chance is situated between consideration of attributions to severely limited ability and to powerful others because it bears an essential similarity to both. Chance attributions resemble attributions to severely limited ability (treated in the last section) in that both give rise to passivity and withdrawal in situations in which activity is likely to lead to success. Moreover, depression, which is commonly regarded as a behavioral manifestation of perceived uncontrollability (Beck, 1967; Seligman, 1975), has been linked both to severely limited ability attributions (see Journal of Abnormal Psychology, February 1978) and to chance attributions (Janoff-Bulman, 1979). Chance attributions are also similar to attributions to powerful others (treated in the next section) in that both involve association with a powerful external agent (in the case of chance attributions, the agent is fate). One indication of the close connection between attributions to chance and attributions to powerful others is the variety of phenomena incorporating both-belief in supernatural powers, witches, demons, fortune-tellers, psychics, mystics, and astrologers. As a consequence of their relation to attributions involving severely limited ability and powerful others, chance attributions are often regarded as particularly indicative of perceived uncontrollability.

Our claim here, as in the preceding section, is that the attributions involved allow for a type of perceived control, referred to here as illusory control. Persons seek to align 
themselves with the force of chance so that they may share in the control exerted by that powerful force. In addition, we maintain that individuals who perceive illusory control in a situation nonetheless recognize the chance determination of that situation. What we are concerned with, then, is not simply the transformation of a perception of chance into a perception of skill. Rather, we believe that people are often aware that chance is operating and that they continue to refer to luck and fate in explaining outcomes, but that they perceive chance as a force with which they can align themselves. Moreover, persons who are most familiar with chance events (e.g., gamblers) are often most susceptible to perceiving them as controllable (Langer, 1977). Thus, the perception of chance as a type of control cannot be dismissed simply as reflecting a lack of familiarity with chance.

\section{The Relationship Between Skill, and Chance}

One of the proofs of illusory control is evidence that persons perceive control in predominantly chance-determined situations. Research by Ayerhoff and Abelson (1976), Langer (1975, 1977), Langer and Roth (1975), and Wortman (1975) provides the necessary evidence. These investigators have shown that under certain conditions subjects respond as if a chance-determined situation were controllable. Specifically, when factors normally associated with skill situations (e.g., choice, effort, task familiarity) are introduced into chance situations in which subjects cannot influence the outcome, an illusion of control is created (Langer, 1977). Manifestations of this illusory control include increased confidence in success, increased risk taking, and self-reported perceptions of control. Naturalistic observations of gambling lead to similar conclusions (Langer, 1977).

The above authors, especially Langer, suggested that under these circumstances, subjects are impressed by the superficial similarity between chance and skill situations and, as a consequence, they fail to distinguish adequately between the two. Support- ing their interpretation are other findings that subjects perceive causal relationships in the absence of objective contingency (Bruner \& Revusky, 1961; Chapman \& Chapman, 1967; Golding \& Rorer, 1972; Smedslund, 1963; Starr \& Katkin, 1969; Ward \& Jenkins, 1965; Hamilton \& Gifford, Note 2). Whereas Langer and her colleagues did not differentiate between subjects' sense of control in skill situations and their sense of control in chance situations (except to say that the latter is inaccurate), we maintain that the former is a perception of primary control and that the latter is, in at least some cases, a perception of secondary control-a sense of participation in the more powerful force of chance.

The studies described above provide some support for the interpretation we propose. First, intelligent and well-educated subjects (Duke University undergraduates in one study, Yale undergraduates in another) were employed in this research, and the chance nature of the tasks was made explicit. Such subjects are likely to perceive the chance nature of the situation accurately. Second, included among the factors that stimulate the illusion of control is passive involvement: The longer people wait for the outcome of a lottery to be announced, the greater their confidence that they will win. Langer (1975) reasoned that in skill situations passive involvement permits time for thought and thus for the development of strategies that enhance one's likelihood of success. Such strategies, however, are unlikely to emerge when one contemplates a lottery in which the outcome will be determined via blind drawing by unknown people in an unknown location. Why then does confidence increase the longer one waits for the outcome? We believe the reason is that, over time, the ticket holder feels increasingly associated with the forces of chance that will operate in the situation. The very fact of passivity underscores the secondary nature of this perceived control. A similar argument applies to Langer's manipulation of subjects' familiarity with the task. If anything, increased familiarity with a chance task should sharpen one's awareness of its chance-determined nature and reduce the likelihood that it will be confused 
with a skill task. But increased familiarity might well increase one's sense of participation in, or alignment with, the task - that is, one's perception of secondary control. Support for our view would be provided by more direct evidence that manipulations such as passive involvement and task familiarity increase illusory control (perceived probability of success) under conditions in which people are fully aware that no direct manipulation is possible and in which no "strategies" have been developed to influence outcomes.

Although the dynamic we propose is different from that proposed by Langer and her colleagues, the two are not incompatible. Illusory control may involve both an association with chance (a secondary process) and a misperception of chance-determined situations as skill-determined (a primary process). Because illusory control is pervasive in the laboratory and in everyday life, both influences are possible.

\section{Locus of Control and Behavior in Chance Situations}

Research on locus of control has repeatedly established a link between externality and various forms of inward behavior (see p. 6). These links take on added significance in light of evidence on the behavior of externals in chance situations. In considering this evidence, it is important to keep in mind that the chance situations are clearly identified as such and that externals, who manifest the most illusory control, are also the most likely to attribute outcomes to chance. Indeed, externality is operationalized, in part, as a tendency to attribute outcomes to chance, luck, and fate (see Lefcourt, 1976; Phares, 1976; Rotter, 1966).

Whereas internals, compared with externals, have consistently been found to prefer and perform better on skill-determined tasks, externals have been shown to express a greater preference for chance tasks than do internals and even to prefer chance tasks to skill tasks (e.g., DuCette \& Wolk, 1973; Kahle, 1980; Schneider, 1968, 1972). Rotter and Mulry (1965) found that externals consult fortune-tellers and have their horoscopes read more often than do internals, and
DuCette and Wolk (1973) found that externals showed a greater preference for an extrasensory perception task than did internals. These authors interpreted their findings as demonstrating externals' greater preference for situations that are congruent with their generalized expectations for control.

Support for the preceding view comes also from findings that externals exhibit "reactance" in situations entailing an impersonal threat, but not in situations entailing a personal threat to control (Cherulnik \& Citrin, 1974). ${ }^{5}$ Impersonal threat, operationalized as denying the subjects a choice of reward due to circumstances beyond the control or intent of the experimenter, was designed to foster attributions to "chance, fate, or the action of another over which [the subject] has no control"' (p. 399). A significant interaction between locus of control and the way in which control was eliminated indicated that externals, compared with internals, reported greater liking for the eliminated reward ("reactance") following the impersonal, chance-like elimination of the reward (it did not arrive in the mail on time) but less liking for the reward when it was eliminated in a personal way (the experimenter decided it was not appropriate for the subject). In explaining their findings, Cherulnik and Citrin suggested that externals expect greater control over impersonal, chance-like rewards than do internals and that it is the violation of this expectation that leads to reactance.

Karabenick and Srull (1978) and Srull and Karabenick (1975) reported findings similar to those above. In both studies, externals cheated more than internals on a task described as chance determined, but an opposite pattern held when the task was described as measuring skill (see also Aronson \& Mettee, 1968). In both skill and chance tasks, insoluble problems were presented, thereby inducing a loss of control similar to that induced in the Cherulnick and Citrin study. Because cheating is a common reaction to perceived loss of control (Brehm, 1966; Wicklund, 1974), these findings sug-

\footnotetext{
${ }^{5}$ Cherulnik and Citrin, like most reactance theorists, use the term freedom rather than control, but these two terms are freely substituted for one another in their writings.
} 
gest that externals perceive their failure at chance tasks as a loss of control; that is, they perceive chance as controllable. Further, self-report findings from the Karabenick and Srull study indicate that externals, but not internals, perceived the chance task as measuring their "ability." This result, the authors noted, is consistent with Rotter and Mulry's (1965) suggestion that externals regard luck as a personal characteristic and are concerned about being lucky. In a more recent study, Karabenick and Addy (1979) found that in chance situations externals were much more likely than internals to rate outcomes as informative of their "dispositions to be lucky or unlucky" (p. 227).

Interactions between locus of control and type of task (chance vs. skill) have also been found with performance level (effort and quality) as the dependent variable. The general pattern in these studies is that externals, compared with internals, try harder and do better in tasks described as chance determined. In two studies (Davis \& Phares, 1967; Rotter \& Mulry, 1965), the superior performance of externals on chance tasks failed to reach significance; in three others (Lefcourt, Lewis, \& Silverman, 1968; Petzel \& Gynther, 1970; Watson \& Baumal, 1967) the difference was significant (but see DuCette \& Wolk, 1973, for conflicting results). In a related vein, Pittman and Pittman (1979) reported that externals performed better than internals under conditions of high helplessness (60 problem-solving trials with noncontingent feedback) but performed worse under conditions of low helplessness (20 trials with noncontingent feedback) and no helplessness (see Gregory, Chartier, \& Wright, 1979, for similar findings). Because the high-helplessness condition in this study is intended to accentuate noncontingency, subjects probably perceived it as one in which outcomes were chance determined. If so, these findings are consistent with those described above: Externals perform better in situations perceived to be chance determined.

The preceding findings, we maintain, are due to externals' greater preference for and feelings of competence in chance situations. An alternative explanation, which merits brief comment, is that externals might be particularly likely to perceive contingency and thus to feel confident in chance situations. Evidence contrary to this view comes from Benassi, Sweeney, and Drevno's (1979) finding that internals, compared with externals, give higher estimates of their success and perceive more control when presented with a chance-determined task that is introduced as being skill determined (a psychokinesis task in which subjects are directed to concentrate so as to affect the outcome). Thus, it appears unlikely that externals overestimate the role of skill in chance-determined situations. Rather, it is something about the perception of chance per se that motivates their performance.

Finally, Maracek and Mettee (1972) replicated the findings, discussed earlier, that persons who expect future failure resist seeing themselves as successful. If success is an indication of ability, Maracek and Mettee reasoned, then the individual accepting success is susceptible to elevated expectations and subsequent disappointment. On the basis of this reasoning, they hypothesized that subjects would not discount success if they could attribute it to luck. Luck, they argued, is an unstable and uncontrollable characteristic that will not affect subsequent expectations. Although their findings supported this hypothesis, there is an alternative interpretation. We realize that many subjects may see luck as unstable and uncontrollable; but some (externals and persons who have experienced acute failure) may be motivated to see it as at least somewhat stable and controllable (cf. Weisz \& Stipek, in press). In the Karabenick and Srull study cited earlier, externals were found to consider themselves "luckier people" (1978, p. 85). These individuals, we suspect, perceive primary control as unlikely or impossible and so adopt stable chance attributions (e.g., "I am a lucky person") that permit secondary control.

\section{Summary}

We have argued in this section that certain individuals neither seek out skill situations nor strive to manipulate the environment; instead, they attempt to align with and rely upon the powerful forces of chance. The 
evidence reviewed here indicates that these individuals tend to manifest a variety of inward behaviors, especially passivity and withdrawal in skill situations, they tend to seek out chance situations, and they tend to be more reactant when adverse events occur because of chance (their perceived ally) than when adverse events occur because of their own actions. Taken together, this evidence suggests that objectively uncontrollable situations, for these individuals, facilitate the perception of and desire for secondary control. Further, this illusory control is revealed in attributions to chance, attributions that satisfy a criterion of proof of the two-process model outlined earlier.

Secondary control, as noted repeatedly in this section, is closely related to external locus of control. The differences that do exist are, in part, historical ones. Originally, external locus of control was assumed to entail a perception of uncontrollability. However, numerous research findings have disconfirmed the perceived uncontrollability assumption, and many locus of control theorists now espouse a position close to the one advocated here. According to the more recent congruence hypothesis, people reserve energy for activities that match the form of control they feel best able to exercise (with externals, for example, focusing on chance activities). Cherulnik and Citrin (1974) put it well: "Externals do not feel powerless, but simply pursue rewards in different avenues" (p. 404). Despite the similarity between this hypothesis and ours, the fact remains that external control was initially defined and in some quarters continues to be thought of as an absence of perceived control. For this reason we prefer the primary/secondary distinction. Indeed, we believe that the confusion between the different definitions of externality mirrors the confusion between perceived uncontrollability and secondary control.

\section{Vicarious Control}

Our explanation of attributions to powerful others and submissive behavior is at once similar to and different from the explanation provided by uncontrollability theorists. According to the proposed model, the attributions and behavior indicate helplessness in the sense that individuals do not perceive themselves as able to alter the environment to fit their desires, but individuals are not helpless in that they derive a perception of secondary, vicarious control from association with powerful others. This association is neither a means to an end nor a method of fulfilling other objectives; rather, the association is desired for its own sake. By aligning themselves with more powerful others, individuals can share in their victories and in their accomplishments-in short, in their control. In a sense they can ride the coattails of these more powerful others. But in order to share in this control, the individuals must become aligned with the more powerful other or become a part of the more powerful group. In other words, they must submit. That such enhanced control can result vicariously from the association with more powerful others is evidenced in such everyday situations as the child who proudly asserts "my daddy is stronger than your daddy," the adolescent cult member whose perception of control rests squarely in the hands of his or her demagogue leader, the ultratraditional housewife who derives a sense of power from her union with her husband, and the regional, chauvinistic follower of sports heroes. (For example, millions of Americans felt a rush of pride when the U.S. Olympic hockey team won the 1980 gold medal). Most significantly, vicarious control is evident in religious phenomena, as, for example, when persons speak of gaining "strength through the Lord."

The notion of vicarious control is related to two existing bodies of theory and research. - One involves the process of identification. The other involves Fromm's theorizing regarding individuation and also the socialpsychological research on self-awareness and deindividuation. Both literatures are reviewed in this section.

\section{Identification}

The construct of identification is similar in several respects to the present notion of vicarious control. Kelman (1958) described identification as having the following properties: (a) It reflects desire for a self-defining 
relationship to another person or a group that is intrinsically desired (rather than being desired because it leads to specific rewards or approval or to the avoidance of specific punishments or disapproval). (b) It is not attributable to the value of the behavior or attitude identified with. (c) It leads to submissiveness, even in the absence of surveillance.

Another description of identification that clarifies its relevance to the construct of vicarious control is provided by Goldschmidt (1974):

In every society, each individual identifies himself with one or more groups of individuals and finds not merely material advantage through such identification, but, more significantly, finds ego gratification (or loss) in response to the fortunes of such groups. (p. 15)

The notion of identification has its origins in psychoanalytic theory. According to Freud (1923/1961), the individual takes on characteristics of others in order to share in their experiences. The psychoanalytic model is so often used to explain character formation and sex-role development that this underlying function-the ability to share in the desirable experiences of others-is sometimes neglected. It is perhaps most evident in Freud's own description of the Oedipal conflict: The son's "identification with his father ... permits the affectionate relationship to the mother to be in a measure retained" (p. 32).

In Freud's view and in related formulations (e.g., Bettelheim's, 1943, work on "identification with the aggressor"; Whiting's, 1959, 1960, work on "status envy"), the importance ascribed to control is unclear. Bandura (1969), however, reinterpreted these formulations in a manner consistent with our position. He maintained that the incentives desired in each case are control and power (see also Maccoby, 1959; Mussen \& Distler, 1959; Parsons, 1955). In support of his claim, Bandura cited evidence indicating that people are more likely to identify with others who possess characteristics suggesting control-competence, expertise, power, and dominance (for a review of these studies, see Bandura, 1969). Another noteworthy feature of Bandura's model is its mention of identificatory behavior other than imitation. $\mathrm{He}$ observed that powerful models are able to "extract subservience from others" (p. 232)-a clear reference to submissive behavior, which is of primary concern here.

Direct support for Bandura's "vicarious control" hypothesis was provided in a now classic study of the determinants of imitation. Bandura, Ross, and Ross (1963) examined situations, designed to simulate those occurring in the nuclear family, in which children could choose to identify with an adult who controlled rewards or an adult who was the envied competitor for the rewards. Because children showed greater imitation of the former adult, Bandura et al. concluded that there is greater support for the social power explanation than for the status envy explanation favored by Whiting. That is, it is the control of rewards, rather than their consumption, that is most desired.

While Bandura's addition of the social power notion to the construct of identification serves to link it more closely to the present construct of vicarious control, his formulation differs from ours in one critical respect. Although rarely explicitly, Bandura at times suggested that individuals who engage in identification do so for instrumental purposes-that is, as a means of primary control (see especially Bandura, 1977). (This is consistent with his preference for the term imitation over the term identification, which he felt has "excess meaning.") Even so, Bandura did, to some extent, depart from the instrumental conceptualization of identification. This is evident in the research he cited to support his claims. For example, he cited Hetherington and Frankie's (1967) finding that children are most likely to imitate the picture preferences of their dominant parent (i.e., the parent rated as more powerful by independent observers) even when it is made clear that their parents will remain unaware of their choices. Such behavior hardly appears instrumental. Rather, the individual seems to be striving for association with the more powerful other and for a form of control that can only be secondary.

\section{Individuation}

Fromm's position. One of the most influential psycho-philosophical books of the 
20th century is Erich Fromm's (1941) Escape From Freedom. ${ }^{6}$ In it, Fromm explored the process of individuation, taking as the prototypical case the separation of infant from caretaker. The key dynamics in this process, according to Fromm, are an increased sense of freedom (similar to the present notion of increased primary control) and an increased sense of loneliness and a diminished sense of power (similar to the present notion of diminished secondary control). Although the separated individual is more independent, at the same time the psychological benefits derived from association with more powerful others are lost. Fromm claimed that persons flee from the individuation process in order to regain a sense of power. He saw evidence of flight from individuation in neurotics' submissiveness and conformity and in historical phenomena such as the Reformation. In the latter, Fromm observed an "emphasis on the wickedness of human nature, the insignificance and powerlessness of the individual and the necessity of the individual to subordinate himself to a power outside of himself"' (p. 38). In capitalism and fascism, too, Fromm saw the individual as attempting to escape from powerlessness through sacrificing the individual self, "either by submission to new forms of authority or by a compulsive conforming to accepted patterns" (p. 135). The ever-present "shoulds" and "oughts" of submissive individuals reflect their attempt to subordinate themselves. Motivating this submission is "the tendency to give up the independence of one's individual self and to fuse one's self with somebody or something outside of oneself in order to acquire the strength which the individual self is lacking" (p. 141).

Fromm viewed masochism as an extreme form of the desire to lose the self. The aim of masochism is symbiosis, "the union of one individual self with another self (or any other power outside of the own self)" (p. 158). Persons desire "to feel inferior and insignificant" out of all proportion to their actual shortcomings. They "belittle themselves," engaging in "self accusation and self criticism" in their aim to make themselves weak and thereby deserving of the association they so ardently seek: "The goal of masochism is not suffering. . . . [ It is] to help the in- dividual escape his unbearable feeling of aloneness and powerlessness" (p. 151). The preponderance of self-blame among depressed individuals, who also perceive extremely little control over outcomes (Abramson \& Sackeim, 1977; Beck, 1967), suggests that they too may be attempting to align themselves with more powerful others.? Fromm summarized his thesis in this way:

The annihilation of the individual self and the attempt to overcome thereby the unbearable feeling of powerlessness are only one side of the masochistic strivings. The other side is the attempt to become a part of a bigger and more powerful whole outside of oneself, to submerge and participate in it. This power can be a person, an institution, God, the nation, conscience, or a psychic compulsion. By becoming part of a power which is felt as unshakably strong, eternal and glamorous, one participates in its strength and glory . . . one gains a new security and a new pride in the participation in the power in which one submerges. (p. 155)

Finally, it should be noted that Fromm did not view alignment with others as an effective long-term means of increasing perceived power: "The escape into symbiosis can alleviate the suffering for a time but it does not eliminate it" (p. 238). Rather, deindividuation leads to a self-perpetuating cycle of greater dependence on others, increased fear of powerlessness, increased conformity,

${ }^{6}$ Fromm's concept of freedom corresponds closely to what we refer to here as primary control. It is a notion of a lack of external constraints and an opportunity to function independently. The reason that people escape it is that they lack the wherewithal to succeed on their own. Averill (1973) contrasts this with another type of freedom: "agreement of the individual with whatever constraints do exist" (p. 299). This type of freedom corresponds to what we refer to as secondary control.

${ }^{7}$ Steinbeck (1963) created a character, Mrs. Trask, who beautifully portrays these dynamics. She is described as "an inside-herself woman" who

used religion as a therapy for the ills of the world ... Her ... god was an expert in punishment. He demanded of her a sacrifice. She searched her mind for some proper egotistical humility and almost happily arrived at the sacrifice-herself. It took her two weeks to write her last letter with revisions and corrected spelling. In it she confessed to crimes she could not possibly have committed and admitted to faults far beyond her capacity. And then, dressed in a secretly made shroud, she went on a moonlight night and drowned herself in a pond so shallow that she had to get down on her knees in the mud and hold her head under water. This required great will power. (p. 15) 
even greater dependence, and so on (pp. 254-255). This cycle is related to our claim that individuals think they must maintain their submissiveness in order to maintain vicarious control. It helps explain the persistence of this form of inward behavior.

Self-awareness and deindividuation. Fromm's case for vicarious control is accompanied by a kaleidescope of historical, political, economic, religious, sociological, and psychological evidence. However, research is needed to substantiate his claims more adequately. The clearest empirical evidence that submissiveness results from a desire to fit in with others can be found in the literature on self-awareness and deindividuation.

Manipulations of self-awareness, such as placing subjects in rooms with mirrors or cameras, exposing them to tape recordings of their voices, and having them write autobiographical sketches, have been found to lead to increased submissiveness (Carver, 1974; Diener \& Wallbom, 1976; Duval, 1976; Rule, Nesdale, \& Dyck, 1975; Scheier, Carver, \& Gibbons, 1979; Wicklund \& Duval, 1971) and feelings of individuation (Diener, 1979; Ickes, Layden, \& Barnes, 1978). The fact that self-awareness also leads to perceptions of decreased choice, lowered self-esteem, and increased helplessness and that these effects are particularly strong following failure (see Brocknér, 1979; Scheier, Carver, \& Gibbons, 1979; Wicklund, 1975, for reviews) suggests that selfawareness serves to focus attention on personal limitations and to increase perceived uncontrollability.

We believe that another dynamic operative in the above studies is the desire for secondary control. Because primary control is perceived as likely to lead to failure, attempts at secondary control are more appealing. The individuation induced by selfawareness serves as a reminder that the individual is separated from powerful others, but it does not act as a barrier to realigning oneself with them. A well-replicated finding is that people exposed to self-awareness manipulations seek to avoid self-awareness, especially following failure (Steenbarger \& Aderman, 1979; Wicklund, 1975). A related finding is that persons high in fear of failure prefer working in a group to working alone (Willerman, Lewit, \& Tellegen, 1960). This avoidance of self-awareness and individuation relates to Fromm's belief that persons seek to escape freedom and to associate with powerful others when they perceive themselves as lacking the wherewithal to function independently, as would be expected to follow from heightened attention to individual limitations. Consistent with these claims, persons do not escape self-awareness and individuation when they see their independent efforts as likely to be successful (Carver, 1979).

Further support for the above claims comes from research on the consequences of decreased individuation. Manipulations designed to decrease individuation (increase "deindividuation") include having subjects wear uniforms, addressing them collectively by a group name, or having them engage in group activities. These manipulations have been found to facilitate an increase in uninhibited behavior, which suggests greater perceived "freedom" (Baron, 1971; Diener, 1979; Festinger, Pepitone, \& Newcomb, 1952; Singer, Brusch, \& Lubin, 1965; Zimbardo, 1970). We believe that this is often a secondary form of freedom, in which individuals feel able to fit in with their environment, rather than a primary form of freedom, in which they feel able to change their environment. Johnson and Downing (1979) provided evidence of deindividuated subjects' desire to fit in and be responsive to environmental cues: Deindividuated people increase shocks administered to a stranger when in the presence of cues supporting aggression (wearing a robe resembling a $\mathrm{Ku}$ Klux Klan uniform), but they decrease shocks administered in the presence of cues supporting nonaggression (wearing a robe resembling a nurse's uniform). Moreover, deindividuated subjects report that they are better able to "flow with the environment and make spontaneous choices" (Diener, 1979). In terms of the proposed model, these subjects seek to fit in and thereby share in the control of the more powerful group.

\section{Summary}

The findings just reviewed suggest the existence of secondary control (in this case a vicarious type) in situations that have in the past been interpreted as reflecting perceived 
uncontrollability. The submissive behavior that was noted is not instrumental, and it is likely to be accompanied by the perception of others as more powerful than the self. Moreover, self-awareness, which typically focuses attention on negative discrepancies between standards and behavior, has been likened to a manipulation of uncontrollability (Wicklund, 1975). Although there is evidence that a type of primary uncontrollability is operative here, we agree with Fromm and with self-awareness and deindividuation theorists that other dynamics are often more influential. In particular, we point to the self's strong desire to submit to others' expectations (as opposed to the lack of desire to assert the self) and to increased enjoyment following deindividuation, which can be attributed, at least in part, to an increase in secondary control. However, we acknowledge that the experimental evidence of vicarious, secondary control is môstly indirect. To strengthen our claims, more direct evidence, including self-reports of increased perceptions of secondary control following deindividuation, is needed.

Further support for our claims may be found in the literature on support systems. Evidence indicating that the family and groups of a religious, fraternal, ideological, social, or political nature offer their members "strength," "buttressing," and "increased self confidence" (cf. Silver \& Wortman, 1980) suggests the existence of the kind of vicarious, secondary control with which we are concerned here. However, the groups may also provide increased primary control by making the individual more confident about himself as an independent agent, so it cannot be assumed that secondary control will prove to be the key dynamic.

\section{Interpretive Control}

Interpretive control refers to the search for meaning and understanding. Because it relates to each of the other kinds of control already considered, an analysis of interpretive control serves as a summary for the article. All of the attributions treated in the previous sections are treated again here. These attributions, we argue, help individuals find meaning in events and thus accept them. The claim that interpretation constitutes a type of control for which people actively strive has been eloquently made by Frankl (1963), who referred to the will to meaning, the achievement of meaning, the sense of courage derived from meaning, and the freedom to choose to accept or reject a particular meaning. Frankl's writings make it clear that the search for meaning is particularly intense under conditions in which there exists minimal primary control.

Janoff-Bulman and Brickman (1980) provided an excellent example of what is referred to here as interpretive control: Many European Jews in the early 1930s who had the opportunity to escape from Europe instead "clung" to the interpretations offered by the Nazis. What looked like "giving up" and "helplessness," Janoff-Bulman and Brickman argued, was actually "persistence at accommodation" (p. 24). People work hard at interpreting events so that they can accept them; in so doing, they may appear to be giving up, but their persistence suggests otherwise. Because considerable energy is devoted to interpretation and because a sense of mastery is associated with the understanding of and ability to accept aversive events, we maintain that interpretation constitutes a secondary type of perceived control (cf. Averill, 1973; Frankl, 1963; Garber, Miller, \& Abramson, 1980).

Several laboratory studies in the area of attribution theory have indicated that persons who perceive a lack of primary control seek secondary control in the form of reasons and explanations. When exposed to failure, "helpless" children (those who attribute failure to severely limited ability) have been shown to engage in a set of interpretations very different than those of "mastery-oriented" children (those who attribute failure to motivational factors such as effort). According to Diener and Dweck (1978), these helpless children tend to look to the causes of their failure, typically doubt their own ability, and are likely to concern themselves with "unmodifiable factors" such as chance. Mastery-oriented children, in contrast, are much more concerned with monitoring their behavior via solution-directed verbalizations and self-instructions. Their interpretations concern the possible solutions, not the causes 
or reasons, for the problem. Looking to causes (which entails the perplexing phenomenon of self-castigation) has the subtle, secondary benefit of providing the individual with a reason and thus an acceptable meaning for his or her condition. Looking to solutions has the obvious, primary benefit of increasing the probability of task success. The distinction between interpretations that explain the event and thereby enable the individual to accept it and those that are solution oriented neatly parallels the distinction between secondary control and primary control.

The Diener and Dweck results also help to clarify other findings in the attribution literature. For example, they may explain why Alloy and Abramson (1979) found that, following failure, subjects in problem-solving situations engaged in fewer complex, solution-oriented hypotheses. The Diener and Dweck results suggest that subjects in the Alloy and Abramson study generated few complex solution-oriented hypotheses because they were busy generating many causeoriented hypotheses (speculations regarding factors contributing to failure). This suggestion closely resembles the conclusion reached by Coyne et al. (1980), whose results indicate that "helpless" subjects "become preoccupied with the explanation of their inability" ( $p .352$ ). Coyne et al. cited numerous other studies in the literature on failure, repression, anxiety, stress, and frustration, which they believe are consistent with this claim. Perhaps most relevant to Diener and Dweck's findings and to the present hypothesis are Pittman and Pittman's (1980) results showing increased "attributional activity" following failure manipulations. In Pittman and Pittman's study, subjects who had experienced failure and who were subsequently administered an attribution task unrelated to the failure experience were more likely to probe for causes underlying the behavior of persons described in the attribution task than were persons not exposed to the failure manipulation. This generalization of the desire for interpretive control is a phenomenon warranting further investigation.

Whereas most of the evidence reviewed thus far in support of secondary control comes from experimental laboratory studies, much of the evidence for interpretive control comes from naturalistic field studies (Silver \& Wortman, 1980). Bulman and Wortman (1977), for example, showed that paralyzed accident victims exert considerable effort to make sense of what has happened to them. All 29 persons interviewed mentioned that they had asked the question, "Why me?" and all but one had developed explanations for their accidents. The six types of explanations they identified-predetermination (fate), probability, chance, God had a reason, deservedness, and reevaluation-parallel in interesting ways the attributions treated in this article. Similarly, Burgess and Holmstrom (1979) found that many rape victims had dealt with the "Why me?" question. They concluded that "coming up with an explanation gives some understanding to the bizarreness of the act and aids in returning some degree of control to the victim" (p. 1270). In contrast to Burgess and Holmstrom's focus on control, Bulman and Wortman concluded that their data indicate a need for an orderly and meaningful world (p. 362). These two positions, however, can be seen as compatible within the present formulation: The striving for secondary control-understanding and thereby accepting the event-sometimes overshadows the striving for primary control-maintaining that the event is or was changeable. That is, both positions may be emphasizing the phenomenon of secondary, interpretive control.

One of the most common explanations found in the previously cited study on paralysis victims was to reevaluate the victimization in a more positive light (Bulman \& Wortman, 1977). These reevaluations were regarded as explanations because they always incorporated a theory as to why the accident had occurred. For example, a focusing on positive outcomes, such as slowing down, learning about other people and life, and choosing their faith, might be accompanied by the thought "The accident may have been for the best." This search for reasons and a purpose following tragic events is also evident in Burgess and Holmstrom's (1979) finding that victims of rape consciously minimize their anxiety. One common strategy is to compare their own rape 
with those of others who were killed, subjected to perversions, or suffered greater violence. Through this "cognitive strategy," Burgess and Holmstrom argued, rape victims are able to render the event more tolerable and acceptable. Similarly, Langer, Janis, and Wolfer (1975) found that when patients were coached to interpret their hospitalization experience as an opportunity for such positive outcomes as rest, diet, and reflection, they rated themselves and were rated by hospital staff as manifesting less stress than did a control group. Like us, these authors emphasize the increased sense of control gained by the coached patients via their ability to reinterpret events.

A related aspect of interpretive control is suggested by evidence that people are particularly unlikely to select positive incentives that they previously believed were difficult to obtain, and similarly, they are particularly likely to select negative incentives that they previously believed were inevitable (Brehm, Stires, Sensenig, \& Shaban, 1966; Ebbesen, Bowers, Phillips, \& Snyder, 1975; Hammock \& Brehm, 1966; Mann \& Dashiell, 1975; also see Silver \& Wortman, 1980). For example, Mann and Dashiell found that males receiving a low draft number (indicating a high probability of being drafted) were more likely to derogate lost alternatives (job, graduate school, travel). Similarly, Ebbesen et al. (1975) found that children were likely to decrease their evaluation of toys, as shown by verbal choice and actual playtime, when the toys were forbidden. The decreased evaluation, they argued, makes the inevitable loss of the toy less frustrating. It is consistent with the two-process model of perceived control that externals, whom we believe are prone to secondary control, are especially likely to devalue unattainable incentives (Lefcourt, 1976). This tendency to alter individual desires and values so that they correspond more closely to the likely outcome may eventually constitute some of the most compelling behavioral evidence of striving for secondary control of the interpretive type.

Our notion of interpretive control is based, in part, on research exploring coping strategies such as denial, intellectualization, and isolation (Holmes \& Houston, 1974; Lazarus \& Alfert, 1964; Lazarus, Opton, Nomikos, \& Rankin, 1965; Speisman, Lazarus, Mordkoff, \& Davison, 1964). This research showed that when people are given a new meaning for an event-for example, if they interpret a painful circumcision rite as something desired by the participants (Lazarus \& Alfert, 1964) or interpret a painful electric shock as an interesting new type of physiological sensation (Holmes \& Houston, 1974) - they experience less stress, as measured by self-reports and physiological indexes. The two-process model suggests that the diminished stress reflects the successful attainment of one type of secondary control-the finding of meaning and thereby the ability to accept potentially aversive events.

The studies on interpretive control indicate that, rather than changing the world, persons sometimes attempt to change themselves (specifically their views) so as to better accept the world. Unfortunately, the research does not make it possible to differentiate the extent to which subjects are seeking meaning per se (which we regard as a type of control) from the extent to which they are seeking the positive thoughts and positive mood that often accompany the achievement of meaning. Some authors, especially Bulman and Wortman (1977) and Langer et al. (1975), emphasize the former; others, especially Lazarus and Launier (1978), emphasize the latter. In the light of Lazarus and Launier's emphasis, it is ironic that they provided some of the most eloquent descriptions of secondary control dynamics. They referred to individuals "trying to modify [themselves] to improve the situation," to "changing one's own characteristics," and to "accommodation" (Lazarus \& Launier, 1978 , p. 314). However, Lazarus and Launier appeared to regard these interpretive efforts as means to an end-positive thoughts and positive mood-rather than as an end in their own right. In contrast, we believe that people often regard interpretive control as intrinsically rewarding. Teasing apart the desire for perceived control and the desire for positive incentives to which this control often leads poses methodological difficulties. To some extent, these problems have already 
been faced by researchers concerned with primary control (Glass \& Singer, 1972; Hiroto \& Seligman, 1975; Seligman, 1975).

There is one study on coping strategies in which the desire for control and the desire for positive ideation were distinguished (Neufeld, 1976). Subjects who were led to believe they were relying on their own coping strategies reported greater "confidence" during stress (viewing a violent film) than did subjects led to believe they were relying on an effective technique devised by the experimenter. In fact, both groups of subjects were given the same coping strategy (clearing the mind). The enhanced effectiveness of the strategy perceived to be self-generated as contrasted with the strategy perceived to be experimenter derived is consistent with our belief that people seek personal control as well as positive ideation.

\section{Summary}

What we refer to here as interpretive control is most likely to occur following failure and in conjunction with attributions typically assumed to reflect perceived uncontrollability. The increased attributional activity found in these situations, we believe, is a clear indication that more than perceived uncontrollability is involved. What is needed to further substantiate our claims is additional self-report evidence that people see themselves as striving for meaning and understanding, and behavioral evidence that people revise their selections of incentives to make them mesh with their new-found interpretations.

\section{Summary and Implications}

\section{Distinguishing Between Secondary Control and Uncontrollability}

The central thesis of this article is that persons perceive and are motivated to obtain secondary control in many situations previously assumed to be characterized by perceived uncontrollability and an absence of motivation for control. Because much of the evidence for secondary control is also evidence of uncontrollability (e.g., prior failure, inward behavior, and attributions to severely limited ability, chance, or powerful others), it is especially important to identify the criteria that distinguish the two phenomena.

A major kind of evidence that is relied upon here, and that should be relied upon in future tests of the model, is behavior indicating persistence and effort. Although we agree with uncontrollability theorists that failure leads to inward behavior, we claim that inward behavior is often motivated and thus that evidence of this motivation is available. We have attempted to show that the effort to obtain secondary control is characterized by various forms of persistent behavior. In seeking predictive control, people may undermine their success so as to avoid rising expectations and subsequent disappointment. In seeking illusory control, people may increase their effort on chance tasks so as to align themselves with the forces of fate and to see themselves as "riding a lucky streak." In seeking vicarious control, people may increase their effort in deindividuated (e.g., group, religious) situations to align themselves with the more powerful others and to join in their strength. Finally, in seeking interpretive control, people may increase their attributional activity and may alter their selection of incentives to make attributions and incentives conform better to the likely outcome. In each case, the persistent behavior occurs within a context of failure and inward behavior and is not itself the kind that we immediately associate with the construct of control. This is the reason why uncontrollability theorists have generally ignored this behavior. We have tried to show, however, that this persistent behavior is characterized by a pervasive effort to fit in effectively with one's environment and to obtain what we refer to as secondary control.

Another kind of evidence needed to support the model developed here is subjective impressions of the benefits of secondary control. The existing self-report data are limited. We believe the reason for this limited data is that most previous researchers have not included appropriate probes to elicit the subjective experience of secondary control. One example of the type of self-report confirmation we would seek is the finding that persons with an external locus of control 
perceive luck as a personal "disposition" and as an "ability." If subjects in other studies cited here had been queried, we suspect that they would have depicted the avoidance of disappointment, the union with powerful others, and the finding of meaning as making them feel effective and, more to the point, as increasing their ability to fit in. Replication of these previous studies with the addition of appropriate self-report and interview measures is one promising way to test the two-process model of perceived control.

\section{Correlates of Secondary Control}

In addition to providing criteria that distinguish secondary control from uncontrollability, the model presented here suggests that there are personality variables that help to distinguish those most likely to exercise each type of control. People seeking secondary control are typically persons who have experienced recurring prior failure or chronic disabilities (e.g., the paralysis victims discussed by Bulman and Wortman, 1977, or persons who are characterized by external locus of control, low self-esteem, or high failure avoidance). We especially suspect the operation of secondary control in persons who manifest perseverative behavior. For example, we speculate that persons labeled mute or autistic strive to avoid disappointment and to gain predictive control by creating a constant, eventless environment and that persons labeled obsessive-compulsive strive to win the approval of powerful forces and to gain vicarious control by submitting to directives and "shoulds." These speculations are supportéd by clinical descriptions of mutism (Lefcourt, 1973), autism, (Park, 1967), and obsessive compulsiveness (Rackman \& Hodgson, 1980; Shapiro, 1965). We believe that these individuals are particularly invested in secondary control, both because of their recurring inability to obtain primary control and because of their success at secondary control.

We argue that perceived uncontrollability, ironically, is especially likely to occur in persons who typically rely on primary control: persons referred to as having a high motivation for success (Atkinson, 1964), persons with an internal locus of control (Lefcourt,
1976, 1980; Rotter, 1966), or "Type A's" (Brunson \& Matthews, 1981; Glass \& Carver, 1980). When these persons are presented with obstacles that are of low salience (Glass, 1977) or of brief duration (Pittman \& Pittman, 1980), they typically respond in a reactant manner, as if they were challenged to exert more primary control. It is only when the obstacle and the resulting failure are salient and of lengthy duration that these individuals' resources are depleted and they are forced to give up. We expect that their giving up is typically accompanied by perceived uncontrollability; this happens because their unsuccessful attempts at primary control are intense and long-lasting and also because they lack the time and energy necessary for mustering secondary control attempts. Some support for this claim comes from Pittman and Pittman's (1979), finding that following prolonged failure, internals showed significantly greater performance deficits than did externals whereas internals exhibited significantly smaller performance deficits in the briefer failure condition. As noted earlier, secondary control is likely to manifest itself in persistence on extremely difficult and chance-like tasks, such as that provided in the prolonged failure condition. If, as we suspect, internals lacked both primary and secondary control in the prolonged failure condition, they would have little reason for persisting. (Also see Janoff-Bulman \& Marshal's, Note 4, evidence of depression among highly competent institutionalized elderly.)

As the above hypothesis suggests, we do not believe that there is a type of individual who chronically perceives uncontrollability. We think of perceived uncontrollability not as constituting a consistent style but as something that persons occasionally slip into and from which they are highly motivated to escape. This view is consistent with the notion elaborated earlier (pp. 6-7) that control is a highly desired and pervasive motive.

Besides suspecting the existence of personality characteristics that predispose persons to secondary control rather than to uncontrollability, we suspect the existence of situational factors that predispose persons to each of these tendencies. Secondary control, we believe, is particularly likely in cases 
of prolonged failure to obtain highly desired and important incentives or cases in which the inability is perceived as permanent (cf. Lazarus \& Launier, 1978; Silver \& Wortman, 1980). The combination of realizing that primary control is not possible and the opportunity to prepare for attempts at secondary control optimizes the likelihood of secondary control. Perceptions that we associate with secondary control have been noted in such settings as old-age homes (Felton \& Kahana, 1974) and concentration camps (DesPres, 1976). Specifically, it has been found that institutionalized elderly who make external attributions report more positive feelings of adjustment than their internal counterparts and that concentration camp victims who try to hold out are those who cling to the hope that ultimately luck will serve them. (Also see Frankl, 1963, for an analysis of the role of secondary control in concentration camp victims.)

Perceptions of uncontrollability, in contrast, should be most likely in cases in which primary control is anticipated but is not attainable or in which opportunities for secondary control are limited (i.e., situations that do not lend themselves to avoidance of disappointment, alignment with chance or powerful others, or finding meaning). One of the factors that may seduce people to wrongly anticipate primary control is that they are not required to test its effectiveness. As long as people are not prompted to exert primary control and to confront its costs and its limitations, they have the luxury of believing in it (Solomon, Holmes, \& McCaul, 1980). They are then prime candidates for perceived uncontrollability when they are finally tested and fail.

\section{Adaptiveness}

The two-process model differs substantially from the uncontrollability model in its conceptualization of adaptiveness. Whereas uncontrollability theorists define adaptiveness in terms of the absolute level of (primary) control, we define adaptiveness in terms of the relative levels of primary and secondary control. If people persist at an insoluble task, uncontrollability theorists would probably suspect an overestimation of the adaptiveness of efforts for primary control; we would add that there may also be an underestimation of the adaptiveness of efforts for secondary control. As an example of the former, Janoff-Bulman and Brickman (1980) cited the scientist who persists in his efforts to solve an impossible problem; an example of the latter is the individual who does not value the ability to predict when his efforts are futile. Underestimations of secondary control could have important consequences because people are reluctant to abandon one type of control (in this case, primary control) when there are no alternatives besides uncontrollability (JanoffBulman \& Brickman, 1980; Lazarus, 1981). Similarly, in the case of people who fail to persist at a task at which they are able to succeed, our analysis differs from the analysis of uncontrollability theorists. We emphasize the possibility that the adaptiveness of secondary control has been overestimated. The shift from a concern with the optimal degree of control to a concern with the optimal balance between different processes of control is one of the most significant implications of the two-process model.

How can we determine what balance is most adaptive? To answer this question, we need to operationalize adaptiveness, an extremely difficult task due to the subjectivity of the values involved. There is considerable disagreement as to the relative benefits and costs associated with different kinds of control (Lazarus, 1981). For example, some people highly value achievement and challenge, which are most fostered by primary control and most jeopardized by secondary control; in contrast, other people highly value physical health, safety, and contentment, for which the opposite is true. Related to the issue of values is the issue of temporal perspective. Different evaluations of adaptiveness will follow from a focus on shortterm effects than will follow from a focus on long-term effects (Lazarus, 1981; Silver \& Wortman, 1980). For example, consider the finding that people "benefit" most (show least stress) when instructed to use a strategy that is already dominant in their hierarchy (Lazarus \& Launier, 1978); this finding might be questioned by persons opting for a more long-term measure of benefit, which 
includes the development of new strategies.

An equally thorny problem in determining what constitutes an optimal balance of control processes is that judgments of adaptiveness depend upon the circumstances in question. In extreme circumstances persons are likely to perceive extremes in primary and secondary control as adaptive. If the situation is one of life or death, one in which the person must attack or be attacked, exclusive primary control may seem appropriate. If, on the other hand, the situation is one of living with a series of fortuitous and painful but irreversible events, then exclusive secondary control may seem appropriate. Even when circumstances are not so extreme, some people will tend to favor primary control and others will tend to favor secondary control. For example, in most competitive and aggressive situations, passivity is detrimental; however, in some of these situations (e.g., when naive persons become involved in con games or when the United States became involved in Vietnam), impulsive, direct action may fuel the problem and make things worse (Rubin \& Brockner, 1975). The multitude of relevant circumstantial factors handicaps the search for general principles (see Silver \& Wortman, 1980, for a review).

Mindful of these complexities, we propose that adaptiveness or "good adjustment" be conceptually defined as a knowledge of how and when to exert the two processes of control and how to integrate them (Janoff-Bulman \& Brickman, 1980). The importance of integration is seen, for example, in the secondary efforts of paralysis victims to find meaning in and to accept aspects of their situation that are irreversible while still devoting efforts to mastery of new problemsolving skills in areas in which primary control is still possible (Silver \& Wortman, 1980). The effectiveness of integration is also evident in the classic aphorism of the Chinese philosopher Lao Tzu: "Those who would conquer must yield; and those who conquer do so because they yield." It is not enough to be proficient at one process of control; in fact, proficiency is a handicap if it interferes with the development of the complementary process. Similar positions have been developed by Janoff-Bulman and
Brickman (1980), by Lazarus (1981), and by Silver and Wortman (1980). The reader is referred to these authors for a more elaborate treatment of the issues involved.

\section{Relationships Between Different Kinds of Secondary Control}

An assumption underlying the two-process model is that the various forms of control subsumed under the rubric secondary are related to one another. For example, we assume that individuals who attribute outcomes to severely limited ability (and who perceive increased control by avoiding disappointment) are more likely to attribute outcomes to chance (and to perceive greater control through aligning with chance) than are individuals who do not attribute outcomes to severely limited ability. In support of this particular link is the fact that both types of persons are especially likely to seek out extremely difficult tasks because such tasks minimize disappointment and maximize the role of chance.

In general, there is little evidence regarding the relationship between different forms of secondary control. There are, however, several factor analytic studies on children that reveal low, but impressively consistent, correlations among inward behaviors. These low-level relationships hold with both "normal" and "clinic" populations (see Achenbach \& Edelbrock, 1978, for a review). A reasonable assumption is that the relationship between these behaviors is similar in magnitude to the relationship between the types of secondary control that, we believe, motivate these behaviors. Research is needed to test this assumption.

Finally, there is the anecdotal evidence of links between the various forms of secondary control. We suggested earlier that beliefs in supernatural powers and in other mysterious forces point to the overlap between illusory and vicarious control. Moreover, we indicated that interpretive secondary control relates to each of the other types of secondary control: It embodies the striving for acceptance of events and situations which lies at the foundation of all attempts for secondary control. Finally, we point to the domain of religion. With its emphasis on fate, mysti- 
cism, powerful other(s), and spiritual meaning, it combines several key manifestations of secondary control. The religious sphere may ultimately prove to be one of the most fruitful for the assessment of the relations among secondary control phenomena.

\section{Therapeutic Implications}

If, as argued here, the two-process model is an appropriate one for understanding a variety of inward behaviors, then certain therapeutic implications follow. Rather than perceiving individuals manifesting these behaviors as lacking in adaptiveness, in ego strength, or, particularly, in control, the emphasis shifts to what they possess - a network of perceptions, motivations, and behaviors herein referred to as secondary control. If secondary control is a major dynamic that is adaptive for many people in many situations, then it is a logical starting point for therapeutic interventions. Ignoring this dynamic and implementing techniques that are irrelevant to it, or that actually oppose it (e.g., trying to force the individual to abandon secondary control), can have negative consequences that might be prevented. It may be important to match therapeutic methods to clients along dimensions suggested by the two-process model. Therapeutic outcome research indicates, for example, that individuals with an external locus of control benefit more from directive interventions whereas individuals with an internal locus of control profit more from nondirective interventions (Abramowitz, Abramowitz, Roback, \& Jackson, 1974; Helweg \& Gaines, 1977). Similar findings have been obtained in research on classroom interventions (Arlin, 1975; Ryback \& Sanders, 1980) and in research on weight-reduction interventions (Wallston, Wallston, Kaplan, \& Maides, 1976).

The uncontrollability model of therapeutic intervention operates under assumptions that differ from ours. The therapist is seen as working with a cleaner slate-or more properly, with a client relatively lacking in motivation for or in perceptions of control on which the therapist might inadvertently trample. The ineffectiveness of some manipulations-for example, the findings of in- creased helplessness following a manipulation of success in a depressed population (Kilpatrick-Tabak \& Roth, 1978)-may be due to the unintended undermining of secondary control (in this case, the undermining of avoidance of disappointment). KilpatrickTabak and Roth's suggestion that subjects in their study may be "particularly prone to the fear of being unable to repeat or sustain successful performance" (p. 150) is consistent with our interpretation. Because of the very different therapeutic implications of the uncontrollability model and the two-process model, further investigation of their relative merits is imperative.

\section{Conclusion}

The major objective here has been to introduce an as yet undeveloped position, rather than to replace an established one. Because the established position-the uncontrollability model-has been taken to task so often in this article, the reader may be left with the mistaken impression that the present authors do not believe in the existence of perceived uncontrollability. This is certainly not the case. What we consistently maintain throughout the article is that there are different types of perceived control and that when primary control is perceived as unattainable, people do not necessarily abandon all efforts at control. As a consequence, stringent criteria should be observed before it is concluded that an individual is completely without motivation for or a perception of control. This is especially true when the attributions and behaviors that are presumed to reflect perceived uncontrollability are highly persistent. In these cases, and in others detailed above, a substantial burden of proof should be felt by those who maintain that perceived control is absent.

\section{Reference Notes}

1. Crandall, V. J. Differences in parental antecedents of internal-external control in children and in young adulthood. Paper presented at the American Psychological Association Convention, Montreal, 1973.

2. Hamilton, D. L., \& Gifford, R. K. Illusory correlation in interpersonal perception: $A$ cognitive basis of stereotypic judgments. Unpublished manuscript, Yale University, 1972.

3. Schulz, R., \& Hanusa, B. H. Attributional deter- 
minants of information seeking after helplessness training. Unpublished manuscript, Institute on Aging, Portland State University, 1979.

4. Janoff-Bulman, R., \& Marshall, G. Coping and control in a population of institutionalized elderly. Unpublished manuscript, University of Massachusetts, Amherst, 1978.

\section{References}

Abramowitz, C. V., Abramowitz, S. F., Roback, H., \& Jackson, C. Differential effectivenss of directive and non-directive group therapies as a function of client internal-external locus of control. Journal of Consulting and Clinical Psychology, 1974, 42, 849853.

Abramson, L., \& Sackeim, H. A. A paradox in depression: Uncontrollability and self blame. Psychological Bulletin, 1977, 84, 838-851.

Abramson, L., Seligman, M., \& Teasdale, J. Learned helplessness in humans: Critique and reformulation. Journal of Abnormal Psychology, 1978, 87, 49-74.

Achenbach, T., \& Edelbrock, C. The classification of child psychopathology: A review and analysis of empirical efforts. Psychological Bulletin, 1978, 85, 1275-1301.

Adler, A. The individual psychology of Alfred Adler (H. C. Ansbacher \& R. R. Ansbacher, Eds.). New York: Harper \& Row, 1956.

Alloy, L. B., \& Abramson, L. Y. Judgment of contingency in depressed and nondepressed students: Sadder but wiser? Journal of Experimental Psychology: General, 1979, 108, 441-485.

Archibald, W. P. Alternative explanations for self-fulfilling prophecy. Psychological Bulletin, 1974, 81, 74-84.

Arlin, M. The interaction of locus of control, classroom structure, and pupil satisfaction. Psychology in the Schools, 1975, 12, 279-286.

Aronson, E., \&. Carlsmith, J. M. Performance expectancy as a determinant of actual performance. Journal of Abnormal and Social Psychology, 1962, 65, 178-182.

Aronson, E, \& Mettee, D. Dishonest behavior as a function of differential levels of induced self-esteem. Journal of Personality and Social Psychology, 1968, 9, 121-127.

Atkinson, J. W. Motivational determinants of risk-taking behavior. Psychological Review, 1957, 64, 359372 .

Atkinson, J. W. An introduction to motivation. Princeton, N.J.: Van Nostrand, 1964.

Averill, J. R. Personal control over aversive stimuli and its relationship to stress. Psychological Bulletin, $1973,80,286-303$.

Ayerhoff, F., \& Abelson, R. P. ESP and ESB: Belief in personal success at mental telepathy. Journal of Personality and Social Psychology, 1976, 34, 240247.

Backman, C. W., \& Secord, P. F. The effect of perceived liking on interpersonal attraction. Human Relations, $1959,12,379-384$.

Bandura, A. Social-learning theory of identificatory pro- cesses. In D. A. Goslin (Ed.), Handbook of socialization theory and research. Chicago: Rand McNally, 1969.

Bandura, A. Self-efficacy: Toward an unifying theory of behavioral change. Psychological Review, 1977, 84, 191-215.

Bandura, A, Ross, D., \& Ross, S. A comparative test of the status envy, social power, and secondary reinforcement theories of identificatory learning. Journal of Abnormal and Social Psychology, 1963, 67, 527-534.

Baron, R. S. Anonymity, deindividuation and aggression (Doctoral dissertation, University of Minnesota, 1970). Dissertation Abstracts International, 1971, 32, 533A. (University Microfilms No. 71-18, 681)

Baum, A., Aiello, J. R., \& Calesnick, L. E. Crowding and personal control: Social density and the development of learned helplessness. Journal of Personality and Social Psychology, 1978, 36, 1000-1011.

Beck, A. T. Depression: Clinical, experimental, and theoretical aspects. New York: Harper \& Row, 1967.

Benassi, V. A., Sweeney, P. D., \& Drevno, G. E. Mind over matter: Percieved success at psychokinesis. Journal of Personality and Social Psychology, 1979, 37, 1377-1386.

Benson, J. S., \& Kennelly, K. J. Learned helplessness: The result of uncontrollable reinforcements or uncontrollable aversive stimuli? Journal of Personality and Social Psychology, 1976, 34, 138-145.

Bettelheim, B. Individual and mass behavior in extreme situations. Journal of Abnormal and Social Psychology, 1943, 38, 417-452.

Brehm, J. W. A Theory of psychological reactance. New York: Academic Press, 1966.

Brehm, J. W., Știres, L. K., Sensenig, J., \& Shaban, J. The attractiveness of an eliminated choice alternative. Journal of Experimental Social Psychology, 1966, 2, 301-313.

Brehm, S. S., \& Brehm, J. W. Psychological reactance: A theory of freedom and control. New York: Academic Press, 1981.

Brickman, P., Linsenmeier, J. A. W., \& McCareins, A. G. Performance enhancement by relevant success and irrelevant failure. Journal of Personality and Social Psychology, 1976, 33, 149-160.

Brock, T., Edelman, S., Edwards, D., \& Schuck, J. Seven studies of performance expectancy as a determinant of actual performance. Journal of Experimental Social Psychology, 1965, 1, 295-310.

Brockner, J. Self-esteem, self-consciousness, and task performance: Replications, extension, and possible explanations. Journal of Personality and Social Psychology, 1979, 37, 447-461.

Bruner, A., \& Revusky, S. H. Collateral behavior in humans. Journal of the Experimental Analysis of Behavior, 1961, 4, 349-350.

Brunson, B. I., \& Matthews, K. A. The Type A coronary-prone behavior pattern and reactions to uncontrollable stress: An analysis of performance strategies, affect, and attributions during failure. Journal of Personality and Social Psychology, 1981, 40, 906918.

Bulman, R. J., \& Wortman, C. B. Attributions of blame and coping in the "real world": Severe accident vic- 
tims react to their lot. Journal of Personality and Social Psychology, 19.77, 35, 351-363.

Burger, J. M., \& Arkin, R. M. Prediction, control and learned helplessness. Journal of Personality and Social Psychology, 1980, 38, 482-491.

Burgess, A. W., \& Holmstrom, L. L. Adaptive strategies and recovery from rape. American Journal of Psychiatry, 1979, 136, 1278-1282.

Carver, C. S. Facilitation of physical aggression through objective self-awareness. Journal of Experimental Social Psychology, 1974, 10, 365-370.

Carver, C. S. A cybernetic model of self-attention processes. Journal of Personality and Social Psychology, $1979 ; 37,1251-1281$.

Chapman, L. J., \& Chapman, J. P. Genesis of popular but erroneous psychodiagnostic categories. Journal of Abnormal Psychology, 1967, 72, 193-204.

Chein, I. The science of behavior and the image of man. New York: Basic Books, 1972.

Cherulnik, P. D., \& Citrin, M. M. Individual differences in psychological reactance: The interaction between locus of control and mode of elimination of freedom. Journal of Personality and Social Psychology, 1974, 29, 398-404.

Cohen, S., Rothbart, M., \& Phillips, S. Locus of control and the generality of learned helplessness in humans. Journal of Personality and Social Psychology, 1976, 34, 1049-1056.

Cottrell, N. B. Performance expectancy as a determinant of actual performance: A replication with a new design. Journal of Personality and Social Psychology, 1965, 2, 685-691.

Coyne, J. C., Metalsky, G. I., \& Lavelle, T. L. Learned helplessness as experimenter-induced failure and its alleviation with attentional redeployment. Journal of Abnormal Psychology, 1980, 89, 350-357.

Davis, W. L., \& Phares, E. J. Internal-external control as a determinant of information-seeking in a social influence situation. Journal of Personality, 1967, 35, 547-561.

DeCharms, R. Personal causation. New York: Academic Press, 1968.

Deci, E. L. Intrinsic motivation. New York: Plenum Press, 1975.

DesPres, T. The survivor. New York: Oxford University Press, 1976.

Deutsh, M., \& Solomon, L. Reactions to evaluations by others as influenced by self-evaluation. Sociometry, $1959,22,93-112$.

Diener, C. I., \& Dweck, C. S. An analysis of learned helplessness: Continuous changes in performance, strategy, and achievement cognitions following failure. Journal of Personality and Social Psychology, 1978, 36, 451-462.

Diener, E. Deindividuation, self-awareness, and disinhibition. Journal of Personality and Social Psychology, 1979, 37, 1160-1171.

Diener, E., \& Wallbom, M. Effects of self-awareness on antinormative behavior. Journal of Research in Personality, 1976, 10, 107-111.

DuCette, J., \& Wolk, S. Cognitive and motivational correlates of generalized expectancies for control. Journal of Personality and Social Psychology, 1973, $26,420-426$.
Duval, S. Conformity on a visual task as a function of personal novelty on attitudinal dimensions and being reminded of the object status of self. Journal of Experimental Social Psychology, 1976, 12, 87-98.

Dweck, C. S. The role of expectations and attributions on the alleviation of learned helplessness. Journal of Personality and Social Psychology, 1975, 31, 674685.

Ebbesen, E. B., Bowers, R. J., Phillips, S., \& Snyder, $M$. Self-control processes in the forbidden toy paradigm. Journal of Personality and Social Psychology, $1975,31,442-452$.

Epstein, S. Expectancy and magnitude of reaction to noxious UCS. Psychophysiology, 1973, 10, 100-107.

Felton, B., \& Kahana, E. Adjustment and situationallybound locus of control among institutionalized aged. Journal of Gerontology, 1974, 29, 3, 295-301.

Festinger, L., Pepitone, A., \& Newcomb, T. Some consequences of deindividuation in a group. Journal of Abnormal and Social Psychology, 1952, 47, 382-389.

Finkelstein, N. W., \& Ramey, C. T. Learning to control the environment in infancy. Child Development. $1977,48,806-819$.

Floor, L., \& Rosen, M. Investigating the phenomenon of helplessness in mentally retarded adults. American Journal of Mental Deficiency, 1975, 79, 565-572.

Frankel, A., \& Snyder, M. Poor performance following unsolvable problems: Learned helplessness or egotism? Journal of Personality and Social Psychology, 1978, 36, 1415-1423.

Frankl, V. E. Man's search for meaning: An introduction to logotherapy. New York: Washington Square Press, 1963.

Freud, S. The ego and the id. In J. Strachey (Ed. and trans.), Standard edition of the complete psychological works of Sigmund Freud (Vol. 19), London: Hogarth Press, 1961. (Originally published, 1923).

Fromm, E. Escape from freedom. New York: Reinhart, 1941 .

Garber, J., Miller, S. M., \& Abramson, L. Y. On the distinction between anxiety and depression: Perceived control, certainty and the probability of goal attainment. In J. Garber \& M. E. P. Seligman (Eds.), Human helplessness: Theory and applications. New York: Academic Press, 1980.

Glass, D. C. Behavior patterns, stress, and coronary disease. Hillsdale, N.J.: Erlbaum, 1977.

Glass, D. C., \& Carver, C. S. Helplessness and the coronary-prone personality. In J. Garber \& M. E. P. Seligman (Eds.), Human helplessness: Theory and applications. New York: Academic Press, 1980.

Glass, D. C., \& Singer, J. E. Urban noise: Experiments on noise and social stressors. New York: Academic Press, 1972.

Goetz, T. E., \& Dweck, C. S. Learned helplessness in social situations. Journal of Personality and Social Psychology, 1980, 39, 246-255.

Golding, S. L., \& Rorer, L. G. "Illusory correlation" and the learning of clinical judgment. Journal of Abnormal Psychology, 1972, 80, 249-260.

Goldschmidt, W. Ethology, ecology, and ethnological realities. In G. V. Coelho, D. A. Hamburg, \& J. E. Adams (Eds.), Coping and adaptation. New York: Basic Books, 1974. 
Gregory, W. L., Chartier, M. C., \& Wright, M. H. Learned helplessness and learned effectiveness: Effects of explicit response cues on individuals differing in personal control expectancies. Journal of Personality and Social Psychology, 1979, 37, 1982-1992.

Griffith, M. Effects of noncontingent success and failure on mood and performance. Journal of Personality, $1977,45,442-458$.

Groos, K. The play of man. New York: Appleton, 1901.

Gunnar-Vongnechten, M. R. Changing a frightening toy into a pleasant toy by allowing the infant to control its actions. Developmental Psychology, 1978, 14, 157-162.

Haimowitz, M. L., \& Haimowitz, N. R. The evil eye: Fear of success. In M. L. Haimowitz \& N. R. Haimowitz (Eds.), Human development: Selected readings (2nd ed.). New York: Crowell, 1966.

Hammock, T., \& Brehm, J. W. The attractiveness of choice alternatives when freedom to choose is eliminated by a social agent. Journal of Personality, 1966, 34, 546-554.

Harter, S. Effectance motivation reconsidered: Toward a developmental model. Human Development, 1978, $21,34-64$.

Helweg, G. C., \& Gaines, L. S. Subject characteristics and preferences for different approaches to psychotherapy: A multivariate study. Journal of Consulting and Clinical Psychology, 1977, 45, 963-964.

Hetherington, E., \& Frankie, G. Effects of parental dominance, warmth, and conflict on imitation in children. Journal of Personality and Social Psychology, $1967,6,119-125$.

Hiroto, D. S. Locus of control and learned helplessness. Journal of Experimental Psychology, 1974, 102, 187-193.

Hiroto, D. S., \& Seligman, M. E. P. Generality of learned helplessness in man. Journal of Personality and Social Psychology, 1975, 31, 311-327.

Holmes, D. S., \& Houston, B. K. Effectiveness of situation redefinition and affective isolation for reducing stress. Journal of Personality and Social Psychology: $1974,29,212-218$.

Ickes, W., Layden, M. A., \& Barnes, R. D. Objective self-awareness and individuation: An empirical link. Journal of Personality, 1978, 46, 146-161.

Janis, I. L. Psychological stress. New York: Wiley, 1958.

Janoff-Bulman, R. Characterological versus behavioral self-blame: Inquiries into depression and rape. Jounal of Personality and Social Psychology, 1979, 37, 1798-1809.

Janoff-Bulman, R., \& Brickman, P. Expectations and what people learn from failure. In N. T. Feather (Ed.), Expectancy, incentive and action. Hillsdale, N.J.: Erlbaum, 1980.

Johnson, J. E. Effects of accurate expectations about sensations on the sensory and distress components of pain. Journal of Personality and Social Psychology. 1973, 27, 261-275.

Johnson, J. E. Stress reduction through sensation information. In I. G. Sarason \& C. D. Spielberger (Eds.), Stress and anxiety (Vol. 2). Washington, D.C.: Hemisphere, 1975.

Johnson, J. E., \& Leventhal, H. Effects of accurate expectations and behavioral instructions on reactions during a noxious medical examination. Journal of Personality and Social Psychology, 1974, 29, 710718.

Johnson, R. D., \& Downing, L. L. Deindividuation and valence of cues: Effects on prosocial and antisocial behavior. Journal of Personality and Social Psychology, 1979, 37, 1523-1538.

Jones, S. C. Self and interpersonal evaluations: Esteem theories versus consistency theories. Psychological Bulletin, 1973, 79, 185-199.

Kahle, L. R. Stimulus condition self-selection by males in the interaction of locus of control and skill-chance situations. Journal of Personality and Social Psychology, 1980, 38, 50-56.

Karabenick, S. A., \& Addy, M. M. Locus of control and sex differences in skill and chance risk-taking conditions. Journal of General Psychology, 1979, $100,215-228$.

Karabenick, S. A., \& Srull, T. K. Effects of personality and situational variation in locus of control on cheating: Determinants of the "congruence effect." Journal of Personality, 1978, 46, 72-95.

Karabenick, S. A., \& Yousseff, Z. I. Performance as a function of achievement motive level and perceived difficulty. Journal of Personality and Social Psychology, 1968, 10, 414-419.

Kelly, G. A. The psychology of personal constructs. New York: Norton, 1955.

Kelman, $H$. Compliance, identification, and internalization: Three processes of attitude change. Journal of Conflict Resolution, 1958, 2, 51-60.

Kessler, J. Psychopathology of childhood. Englewood Cliffs, New Jersey: Prentice-Hall, 1966.

Kilpatrick-Tabak, B., \& Roth, S. An attempt to reverse performance deficits associated with depression and experimentally induced helplessness. Journal of $A b$ normal Psychology, 1978, 87, 141-154.

Klein, D. C., \& Seligman, M. E. P. Reversal of performance deficits in learned helplessness and depression. Journal of Abnormal Psychology, 1976, 85, 11 26.

Klinger, E. Consequences of commitment to and disengagement from incentives. Psychological Review, $1975,82,1-25$.

Koller, P. S., \& Kaplan, R. M. A two-process theory of learned helplessness. Journal of Personality and Social Psychology, 1978, 36, 1177-1183.

Kukla, A. Performance as a function of resultant achievement motivation (perceived ability) and perceived difficulty. Journal of Research in Personality, 1974, 7, 374-383.

Langer, E. J. The illusion of control. Journal of Personality and Social Psychology, 1975, 32, 311-328.

Langer, E. J. The psychology of chance. Journal of the Theory of Social Behavior, 1977, 7, 185-207.

Langer E. J., \& Benevento, A. Self-induced dependence. Journal of Personality and Social Psychology, 1978, 36, 886-893.

Langer, E. J., Janis, I. L., \& Wolfer, J. Reduction of psychological stress in surgical patients. Journal of Experimental Social Psychology, 1975, 11, 155-165.

Langer, E. J., \& Rodin, J. The effects of choice and enhanced personal responsibility: A field experiment 
in an institutional setting. Journal of Personality and Social Psychology, 1976, 34, 191-198.

Langer, E. J., \& Roth, J. Heads I win, tails it's chance: The illusion of control as a function of the sequence of outcomes in a purely chance task. Journal of Personality and Social Psychology, 1975, 32, 951-955.

Lazarus, R. S. Psychological stress and the coping process. New York: McGraw-Hill, 1966.

Lazarus, R. S. The costs and benefits of denial. In $\mathbf{S}$. Breznitz (Ed.), Denial of stress. New York: International Universities Press, 1981.

Lazarus, R. S., \& Alfert, E. The short-circuiting of threat. Journal of Abnormal and Social Psychology, $1964,69,195-205$.

Lazarus, R. S., \& Launier, R. Stress-related transactions between person and environment. In L. A. Pervin \& M. Lewis (Eds.), Perspectives in interactional psychology. New York: Plenum Press, 1978.

Lazarus, R. S., Opton, E. M., Nomikos, M. S., \& Rankin, N. O. The principle of short circuiting of threat: Further evidence. Journal of Personality, 1965, 33, 622-635.

Lefcourt, H. M. The function of the illusions of control and freedom. American Psychologist, 1973, 28, 417425.

Lefcourt, H. M. Locus of control: Current trends in theory and research. Hillsdale, New Jersey: Erlbaum, 1976.

Lefcourt, H. M. Personality and locus of control. In J. Garber \& M. E. P. Seligman (Eds.), Human helplessness: Theory and applications. New York: Academic Press, 1980.

Lefcourt, H. M., Lewis, L., \& Silverman, I. W. Internal versus external control of reinforcement and attention in a decision-making task. Journal of Personality, $1968,36,663-682$.

Lepper, M. R., Greene, D., \& Nisbett, R. E., Undermining children's intrinsic interest with extrinsic rewards: A test of the "overjustification" hypothesis. Journal of Personality and Social Psychology, 1973, 28, 129-137.

Leventhal, H., Brown, D., Shacham, S., \& Engquist, G. Effects of preparatory information about sensenations, threat of pain, and attention on cold pressor distress. Journal of Personality and Social Psychology, 1979, 37, 688-714.

Maccoby, E. E. Role-taking in childhood and its consequences for social learning. Child Development, 1959, 30, 239-252.

Malinowski, B. Magic, science, and religion. New York: Anchor Books, 1955.

Mann, L., \& Dashiell, T. Reactions to the draft lottery: A test of conflict theory. Human Relations, 1975, 28, 155-173.

Maracek, J., \& Mettee, D. R. Avoidance of continued success as a function of self-esteem, level of esteem certainty, and responsibility for success. Journal of Personality and Social Psychology, 1972, 22, 98-107.

Marks, I. Phobias and obsessions. In J. D. Maser \& M. E. P. Seligman (Eds.), Psychopathology: Experimental models. San Francisco: Freeman, 1977.

Mettee, D. R. Rejection of unexpected success as a function of the negative consequences of accepting success.
Journal of Personality and Social Psychology, 1971, 17, 332-341.

Miller, S. M. Why having control reduces stress: If I can stop the roller coaster, I don't want to get off. In J. Garber \& M. E. P. Seligman (Eds.), Human helplessness: Theory and applications. New York: Academic Press, 1980.

Miller, S. M., \& Grant, R. P. The blunting hypothesis: A theory of predictability and human stress. In P. $O$. Sjoder, S. Bates, \& W. R. Dockens (Eds.), Trends in behavior therapy. New York: Academic Press, 1980.

Miller, W. R., \& Seligman, M. E. P. Depression and learned helplessness in man. Journal of Abnormal Psychology, 1975, 84, 228-238.

Mussen, P. H., \& Distler, L. Masculinity, identification, and father-son relationships. Journal of Abnormal and Social Psychology, 1959, 59, 350-356.

Neufeld, R. W. J. Evidence of stress as a function of experimentally altered appraisal of stimulus aversiveness and coping adequacy. Journal of Personality and Social Psychology, 1976, 33, 632-646.

Park, C. C. The siege, New York: Harcourt, Brace \& World, 1967.

Parsons, T. Family structure and the socialization of the child. In T. Parsons \& R. F. Bales (Eds.), Family, socialization, and interaction process. Glencoe, III.: Free Press, 1955.

Petzel, T. P., \& Gynther, M. D. Effects of internalexternal locus of control and skill or chance instructional sets on task performance. Journal of General Psychology, 1970, 82, 87-93.

Phares, E. J. Locus of control in personality. Morristown, N.J.: General Learning Press, 1976.

Piaget, J. Piaget's theory, In P. H. Mussen (Ed.), Carmichael's manual of child psychology (3rd ed., Vol. 2). New York: Wiley, 1970.

Pittman, N. L., \& Pittman, T. S. Effect of amount of helplessness training and internal-external locus of control on mood performance. Journal of Personality and Social Psychology, 1979, 37, 39-47.

Pittman, T. S., \& Pittman, N. L. Deprivation of control and the attribution process. Journal of Personality and Social Psychology, 1980, 39, 377-389.

Rackman, S. J., \& Hodgson, R. J. Obsessions and compulsions (Century Psychology Series). Englewood Cliffs, N.J.: Prentice-Hall, 1980.

Rodin, J., Rennert, K., \& Solomon, S. Intrinsic motivation for control: Fact or fiction. In A. Baum, J. E, Singer, \& S. Valios (Eds.), Advances in environmental psychology II. Hillsdale, N.J.: Erlbaum, 1980.

Roth, S. A revised model of learned helplessness in humans. Journal of Personality, 1980, 48, 103-133.

Roth, S., \& Bootzin, R. R. The effects of experimentally induced expectancies of external control: An investigation of learned helplessness. Journal of Personality and Social Psychology, 1974, 29, 253-264.

Roth, S., \& Kubal, L. Effects of non-contingent reinforcement on tasks of differing importance: Facilitation and learned helplessness. Journal of Personality and Social Psychology, 1975, 32, 680-691.

Rothbaum, F. Children's clinical syndromes and generalized expectations of control. In $\mathrm{H}$. W. Reese \& L. P. Lipsett (Eds.), Advances in child development 
and behavior (Vol. 15). New York: Academic Press, 1980.

Rothbaum, F. The effect of sufficiency and necessity on perceptions of control and responsibility. Journal of Personality, 1981, 49, 85-100.

Rothbaum, F., Wolfer, J., \& Visintainer, M. Coping behavior and control in children. Journal of Personality, 1979, 47, 118-135.

Rotter, J. B. Generalized expectancies for internal versus external control of reinforcement, Psychological Monographs, 1966, 80, 1-28.

Rotter, J. B., \& Mulry, R. C. Internal versus external control of reinforcement and decision time. Journal of Personality and Social Psychology, 1965, 2, 598604.

Rubin, J. Z., \& Brockner, J. Factors affecting entrapment in waiting situations: The Rosencrantz-Guildenstern effect. Journal of Personality and Social Psychology, 1975, 32, 1054-1063.

Rule, B. G., Nesdale, A. R., \& Dyck, R. Objective selfawareness and differing standards of aggression. Representative Research in Social Psychology, 1975, 6. 82-88.

Ryback, D., \& Sanders, J. J. Humanistic vs. traditional teaching styles and student satisfaction. Journal of Humanistic Psychology, 1980, 1, 87-90.

Scheier, M. F., Carver, C. S., \& Gibbons, F. X. Selfdirected attention, awareness of bodily states, and suggestibility. Journal of Personality and Social Psychology, 1979, 37, 1576-1588.

Schneider, J. M. Skill versus chance activity preference and locus of control. Journal of Consulting and Clinical Psychology, 1968, 32, 333-337.

Schneider, J. M. Relationship between locus of control and activity preferences: Effects of masculinity, activity, and skill. Journal of Consulting and Clinical Psychology, 1972, 38, 225-230.

Schulz, R. Aging and control. In J. Garber \& M. E. P. Seligman (Eds.), Human helplessness: Theory and applications. New York: Academic Press, 1980.

Seligman, M. E. P. Helplessness: On depression, development and death. San Francisco: Freeman, 1975.

Shaban, J., \& Jecker, J. Risk preference in choosing an evaluator: An extension of Atkinson's achievementmotivation model. Journal of Experimental Social Psychology, 1968, 4, 35-45.

Shapiro, D. Neurotic styles. New York: Basic Books, 1965.

Shontz, F. C. The psychological aspects of physical illness and disability. New York: Macmillan, 1975.

Sidle, A., Moos, R., Adams, J., \& Cady, P. Development of a coping scale. Archives of General Psychiatry, $1969,20,226-232$.

Silver, R. L., \& Wortman, C. B. Coping with undesirable life events. In J. Garber \& M. E. P. Seligman (Eds.), Human helplessness: Theory and applications. New York: Academic Press, 1980.

Singer, J. E., Brusch, C. A., \& Lubin, S. C. Some aspects of deindividuation: Identification and conformity. Journal of Experimental Social Psychology, $1965,1,356-378$.

Smedslund, J. The concept of correlation in adults.
Scandinavian Journal of Psychology, 1963, 4, 165173.

Snyder, M. L., Stephan, W. G., \& Rosenfield, D. Attributional egotism. In J. H. Harvey, W. Ickes, \& R. F. Kidd (Eds.), New directions in attribution research (Vol. 2). Hillsdale, N.J.: Erlbaum, 1978.

Snyder, M., \& Wicklund, R. A. Attribution ambiguity. In J. H. Harvey, W. Ickes, \& R. F. Kidd (Eds.), New Directions in attribution research (Vol. 3), Hillsdale, N.J.: Erlbaum, 1981.

Solomon, S., Holmes, D. S., \& McCaul, K. D. Behavioral control over aversive events: Does control that requires effort reduce anxiety and physiological arousal? Journal of Personality and Social Psychology, 1980, 39, 729-736.

Speisman, J. C., Lazarus, R. S., Mordkoff, A. M., \& Davidson, L. A. The experimental reduction of stress based on ego-defense theory. Journal of Abnormal and Social Psychology, 1964, 68, 361-380.

Srull, T. K., \& Karabenick, S. A. Effects of personalitysituation locus of control congruence. Journal of Personality and Social Psychology, 1975, 32, 617-628.

Starr, B. J., \& Katkin, E. S. The clinician as an aberrant actuary: Illusory correlation and incomplete sentences blank. Journal of Abnormal Psychology, 1969, 74, 670-675.

Steenbarger, B. N., \& Aderman, D. Objective selfawareness as a non-aversive state: Effect of anticipating discrepancy reduction. Journal of Personality, 1979, 47, 330-339.

Steinbeck, J. East of Eden. New York: Viking Press, 1963.

Tennen, H., \& Eller, S. J. Attributional components of learned helplessness and facilitation. Journal of Personality and Social Psychology, 1977, 35, 4, 265271.

Thornton, J. W., \& Jacobs, P. D. Learned helplessness in human subjects. Journal of Experimental Psychology, 1971, 87, 369-372.

Trope, Y. Seeking information about one's own ability as a determinant of choice among tasks. Journal of Personality and Social Psychology, 1975, 32, 10041013.

Trope, Y., \& Brickman, P. Difficulty and diagnosticity as determinants of choice among tasks. Journal of Personality and Social Psychology, 1975, 31, 918 925.

Wallston, B. S., Wallston, K. A., Kaplan, G. D., \& Maides, S. A.: Development and validation of the Health Locus of Control (HLC) Scale. Journal of Consulting and Clinical Psychology, 1976, 44, 580585.

Ward, W. C., \& Jenkins, H. M. The display of information and the judgment of contingency. Canadian Journal of Psychology/Revue Canadienne de Psychologie, 1965, 19, 231-241.

Watson, D., \& Baumal, E. Effects of locus of control and expectation of future control upon present performance. Journal of Personality and Social Psychology, 1967, 6, 212-215.

Watson, J. S. Memory and "contingency analysis" in infant learning. Merrill-Palmer Quarterly, 1967, 13, 55-76.

Weiner, B. (Ed.). Achievement motivation and attri- 
bution theory. Morristown, N.J.: General Learning Press, 1974.

Weiss, J. M. Effects of coping responses on stress. Journal of Comparative and Physiological Psychology, $1968,65,251-260$.

Weiss, J. M. Effects of coping behavior in different warning signal conditions on stress pathology in rats. Journal of Comparative and Physiological Psychology, 1971, 77, 1-13. (a)

Weiss, J. M. Effects of coping behavior with and without a feedback signal on stress pathology in rats. Journal of Comparative and Physiological Psychology, 1971, 77, 22-30. (b)

Weiss, J. M. Effects of punishing and coping response (conflict) on stress pathology in rats. Journal of Comparative and Physiological Psychology, 1971, 77, 1421. (c)

Weisz, J. R. Perceived control and learned helplessness among mentally retarded and nonretarded children: A developmental analysis. Developmental Psychology, 1979, 15, 311-319.

- Weisz, J. R. Developmental change in perceived control: Recognizing noncontingency in the laboratory and perceiving it in the world. Developmental Psychology, $1980,16,385-390$.

Weisz, J. R. Illusory contingency in children at the state fair. Developmental Psychology, 1981, 17, 481-489.

Weisz, J. R. Learned helplessness and the retarded child. In E. Zigler \& D. Balla (Eds.), Mental retardation: The developmental-difference controversy. Hillsdale, N.J.: Erlbaum, in press.

Wiesz, J. R., \& Stipek, D. J. Competence, contingency, and the development of perceived control. Human Development, in press.

White, R. Motivation reconsidered: The concept of competence. Psychological Review, 1959, 66, 297-333.

Whiting, J. W. M. Sorcery, sin, and the superego. In M. R. Jones (Ed.), Nebraska Symposium on Motivation (Vol. 6). Lincoln: University of Nebraska Press, 1959.

Whiting, J. W. M. Resource, mediation and learning by identification. In I. Iscoe \& H. W. Stevenson
(Eds.), Personality development in children. Austin: University of Texas Press, 1960, 112-126.

Wicklund, R. A. Freedom and reactance. New York: Wiley, 1974.

Wicklund, R. A. Objective self-awareness. In L. Berkowitz (Ed.), Advances in experimental social psychology (Vol. 8). New York: Academic Press, 1975.

Wicklund, R. A., \& Duval, S. Opinion change and performance facilitation as a result of objective selfawareness. Journal of Experimental Social Psychology, 1971, 7, 319-342.

Willerman, B., Lewit, D., \& Tellegen, A. Seeking and avoiding self-evaluation by working individually or in groups. In D. Willmer (Ed.), Decisions, values and groups. New York: Pergamon Press, 1960.

Wolman, B. B. (Ed.). Handbook of clinical psychology. New York: McGraw-Hill, 1965.

Wortman, C. B. Some determinants of perceived control. Journal of Personality and Social Psychology, $1975,31,282-294$.

Wortman, C. B., \& Brehm, J. W. Responses to uncontrollable outcomes: An integration of reactance theory and the learned helplessness model. Advances in Experimental Social Psychology, 1975, 8, 277-336.

Wortman, C. B., Costanzo, P. R., \& Witt, R. T. Effect of anticipated performance on the attribution of causality to self and others. Journal of Personality and Social Psychology, 1973, 27, 372-381.

Yando, R., \& Zigler, E. Outerdirectedness in the problem-solving of institutionalized and noninstitutionalized normal and retarded children. Developmental Psychology, 1971, 4, 277-288.

Zimbardo, P. G., The human choice: Individuation, reason, and order versus deindividuation, impulse, and chaos. In W. J. Arnold \& D. Levine (Eds.), Nebraska Symposium on Motivation (Vol, 17). Lincoln: University of Nebraska Press, 1970.

Zuckerman, M. Attribution of success revisited or: The motivational bias is alive and well in attribution theory. Journal of Personality, 1979, 47, 245-287.

Received September 5, 1980 Revision received May 5, 1981 